\title{
Tecnología lítica en las sociedades tardías de Antofagasta de la Sierra (Puna Meridional Argentina)
}

\section{RESUMEN}

Hacia ca. 1000 años AP en la microrregión de Antofagasta de la Sierra (provincia de Catamarca, Puna Meridional Argentina) se acentúan las prácticas agrícolas en la subsistencia de las poblaciones junto a un creciente sedentarismo e incremento demográfico. Estos cambios habrían implicado nuevas estrategias tecnológicas. En el presente trabajo expondremos y discutiremos las tendencias tecnológicas observadas a partir del análisis técnico-morfológico y morfológico-funcional de los conjuntos instrumentales de dos sitios de la microrregión asignados a momentos posteriores a ca. 1000 años AP: La Alumbrera y Campo Cortaderas 1.

Palabras claves: sociedades agropastoriles - incremento de la agricultura - riesgo - mecanismos buffer - tecnología lítica.

\begin{abstract}
Ca. 1000 years BP, in the microregion of Antofagasta de la Sierra (Catamarca Province, Southern Puna of Argentina) the importance of agricultural practices in the subsistence of the people increased along with a progressive sedentary settlement pattern and demographic increment. These changes might have implied new technological strategies. In this paper we will expose and discuss lithic technological trends drawn from a technic-morphological and morphological-functional analysis of the instruments from two sites of the microregion ascribed to moments after ca. 1000 years BP: La Alumbrera y Campo Cortaderas 1 .
\end{abstract}

Key words: agropastoral societies - agricultural increment - risk - buffer mechanisms - lithic technology.

Recibido: septiembre 2006. Aceptado: febrero 2007.

\section{Introducción}

Se ha propuesto que hacia $c a .1000$ años AP en la microrregión de Antofagasta de la Sierra la agricultura habría adquirido mayor importancia

1 CONICET - Instituto Nacional de Antropología y Pensamiento Latinoamericano. 3 de Febrero 1378, C1426BJN, Buenos Aires, ARGENTINA. Email: alejandra.elias2@gmail.com en la subsistencia, junto a un incremento del sedentarismo y crecimiento poblacional (Olivera y Podestá 1993; Olivera y Vigliani 2000-2002). La intensificación y extensificación de la agricultura habría implicado que los riesgos de mediano y largo plazo -ya postulados por Escola (1996) para el Formativo- asociados a las actividades productivas agropastoriles adquirieran una mayor importancia, al igual que los mecanismos orientados a resolverlos (Elías 2005 Ms; Escola et al. 2006 Ms). Paralelamente, la caza y el pastoreo no habrían dejado de jugar un rol en la subsistencia (Olivera 1998; Olivera et al. 2003-2005). Sugerimos que esto habría llevado a una importante diversificación de actividades y requerido de una organización y ponderación del tiempo invertido en cada una de ellas por parte de las sociedades.

Considerando la tecnología en un sentido amplio, como un componente dinámico de un sistema mayor, interrelacionado con otros dominios (económico, ideológico, político, social; Nelson 1995), los cambios en las actividades de subsistencia habrían implicado otros en las estrategias tecnológicas de las sociedades de nuestro interés, entre los que podemos contar la reorganización del tiempo destinado a distintas tecnologías (cerámica, lítica, de irrigación, de almacenaje) en función de su grado de compromiso con la subsistencia de la sociedad y los mecanismos de manejo del riesgo.

En este contexto nos preguntamos cuáles habrían sido las estrategias y decisiones tecnológicas líticas tomadas por las sociedades tardías e incaicas. Intentaremos acercarnos al tiempo invertido en las distintas etapas de producción de los instrumentos identificados en dos conjuntos relevados en superficie en sitios asignados a momentos tardíos y posteriores: Campo Cortaderas 1 (CCT1) y La Alumbrera (LA). Asimismo, cuando sea posible, compararemos los resultados con los obtenidos por Escola (2000) en el conjunto formativo de Casa Chávez Montículos 1 (CCHM1). 


\section{La microrregión de Antofagasta de la Sierra}

Esta microrregión se ubica en el extremo noroeste de la provincia de Catamarca (Figura 1) en la Puna Meridional Argentina, que abarca también el sector sudoccidental de la provincia de Jujuy y parte de la provincia de Salta (Albeck 2001). Forma parte de la Puna Salada, la cual se caracteriza por presentar condiciones agudas de aridez e inestabilidad ambiental (Núñez y Santoro 1988), siendo el sector meridional de la Puna argentina uno de los más representativos en este sentido (Olivera y Elkin 1994). Como en toda la Puna, la distribución de los recursos no es homogénea, distinguiéndose áreas de alta concentración de nutrientes (ZCN: zonas de concentración de nutrientes, sensu Yacobaccio 1994). Las ZCN se caracterizan por tener una mayor diversidad y densidad de recursos en general (aunque no concentran todos los recursos necesarios para una población), como así también una mayor disponibilidad de recursos fijos básicos, como agua y leña, y por un alto grado de protección contra los factores atmosféricos. ZCN son las quebradas, lagunas, bolsones fértiles y vegas, y se hallan separadas entre sí por las formaciones de estepas (Yacobaccio 1994). ${ }^{2}$

En nuestra área de investigación se han distinguido tres sectores con alta concentración de recursos (Olivera y Podestá 1993): a) Fondo de Cuenca (3400-3500 m.snm); b) Sectores Intermedios (3550-3900 m.snm); y c) Quebradas de Altura (3900-4600 m.snm). Estos presentan diferencias ecológicas y topográficas entre sí, con una oferta diferencial de recursos faunísticos, vegetales y minerales (Olivera y Podestá 1993). La intensidad y forma de aprovechamiento de estas $\mathrm{ZCN}$ por parte de las poblaciones humanas fue cambiando a lo largo del tiempo en la medida que ellas mismas experimentaban cambios en su medio ambiente, subsistencia, demografía y organización social y política (Olivera y Vigliani 2000-2002; Olivera et al. 2003-2005; Olivera 2006).

\section{Antecedentes de investigación}

Proceso de cambio cultural en Antofagasta de la Sierra

Se ha planteado que desde hace $c a .2000$ años AP la agricultura habría adquirido mayor importancia en la subsistencia (Olivera y Podestá 1993), especialmente

2 Estas condiciones se incrementan hacia la Puna Meridional Argentina en donde la concentración de nutrientes se da en espacios muy restringidos en un marco desértico de extrema aridez (Yacobaccio 1994). hacia ca. 1000 años AP y con la llegada de los incas a la microrregión (Olivera y Vigliani 2000-2002). Este proceso fue acompañado por un aumento del sedentarismo en relación al incremento gradual de la presión poblacional y de la agricultura (Olivera y Vigliani 2000-2002). La progresiva mayor incidencia del cultivo en las economías puneñas y el aumento poblacional, acompañados por la restricción de la movilidad y una mayor cuota de sedentarismo, habrían iniciado una paulatina modificación en la organización social y política de los grupos llevando a una creciente concentración y burocratización del poder y a un patrón concentrado de asentamiento como en el sitio La Alumbrera (Olivera y Vigliani 2000-2002).

Respecto del por qué de estos cambios, investigaciones recientes sobre el paleoambiente microrregional han llevado a relacionarlos con el ambiente más árido que empieza a manifestarse hacia $c a$. 1650-1700 años AP. Frente a esta aridez progresiva las sociedades de Antofagasta de la Sierra habrían elegido incrementar el rendimiento a partir de nuevas tecnologías, en lugar de migrar a otros ambientes más propicios o disminuir su número (Olivera et al. 2004).

Con la llegada de los incas ocurrieron nuevas modificaciones en la infraestructura agrícola, caracterizadas por la ampliación y complejización de todo el sistema de producción (Olivera y Vigliani 2000-2002).

Tecnología lítica entre las sociedades agropastoriles de Antofagasta de la Sierra

Autores como Dellino (1998), Escola (2000) y Pérez (2003), entre otros, han llevado a cabo estudios sobre la evidencia arqueológica lítica de varios sitios asignados a momentos formativos ( $c a$. 2500-1200 años AP) en la microrregión (Casa Chávez Montículos 1 y 4 y sitios de la quebrada de Real Grande). Escola (2000) propone que las nuevas situaciones organizativas postuladas para momentos formativos en Antofagasta de la Sierra, caracterizadas por el desarrollo de un alto control efectivo de los recursos de subsistencia a través de prácticas agropastoriles (Olivera 1992), habrían provocado un cambio en el riesgo de corto plazo asociado a la subsistencia, con la disminución del estrés temporal y de la impredecibilidad en la obtención de los recursos, propios de las actividades de caza y recolección. Plantea que las sociedades agropastoriles formativas se habrían enfrentado a nuevos riesgos (productivos y de trabajo o mano de obra), cuyo manejo habría requerido la 


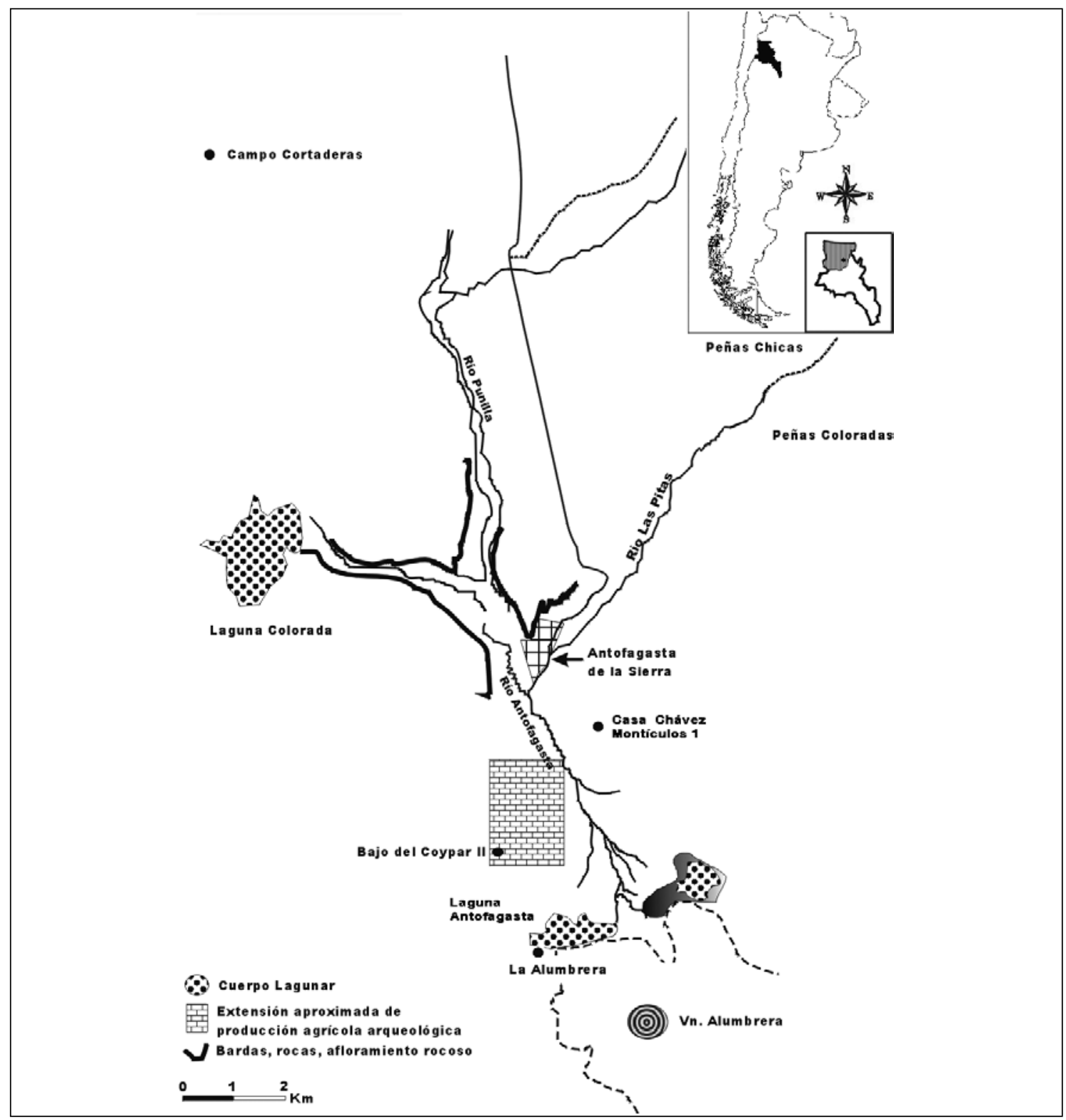

Figura 1. Ubicación de los sitios La Alumbrera y Campo Cortaderas 1.

implementación de nuevas estrategias o respuestas socioculturales (Escola 1996). Entre estas se cuentan el mejoramiento de la capacidad de carga del terreno, diversificación de las actividades productivas, intercambio, movilidad, almacenamiento y mecanismos sociales de cooperación (Browman 1987a, 1987b, 1994; Fernández 1992; McCorkle 1992; Göbel 1994; Escola 1996). Frente a estas diversas actividades, los grupos habrían minimizado el tiempo invertido en la tecnología lítica y la expeditividad con su baja inversión de esfuerzo tecnológico habría sido una solución mínimamente eficiente en la producción de instrumentos (Escola 1996, 2000).

Sin embargo, no toda la evidencia lítica de las sociedades formativas de la microrregión es susceptible de ser enmarcada como producto de estrategias expeditivas. Algunos componentes de estos conjuntos líticos podrían caracterizarse como resultado de estrategias conservadas. Es el caso de las puntas de proyectil (Escola 2000, 2002), los artefactos asociados a la molienda (Babot 2004), las grandes lascas con 
retoque (Escola 2000) y las palas y/o azadas (Pérez 2003). Este último autor plantea que las palas y/o azadas de contextos formativos

"(...) eran instrumentos conservados ya que eran mantenidos, estandarizados y enmangados, lo cual implicaría un costo medido en inversión de tiempo y energía dedicada a la obtención del producto final (...)" (2003: 119-120).

Babot (2004: 267) señala tendencias similares entre los artefactos de molienda. Después de ca.3200 años AP sugiere que existió una búsqueda deliberada de eficiencia entre estos ítems y que tuvo lugar una importante intensidad de molienda. Las razones que explicarían estos cambios según esta investigadora son: a) la necesidad de disminuir el tiempo invertido en el procesamiento con el fin de participar en otras tareas asociadas a situaciones de riesgo de trabajo o de mano de obra; y b) la necesidad de mayor cantidad de producto molido o un número mayor de gente alimentándose del mismo.

Particularmente, consideramos que las constricciones propias de las actividades agrícolas relacionadas a las limitaciones temporales del ciclo productivo, sobre todo en un ambiente de marcada estacionalidad como el puneño, también podrían explicar las particulares características de los instrumentos e implementos asociados a las mismas (palas y/o azadas, manos, molinos, morteros) (Elías 2006).

Finalmente, otro factor que habría influido en las elecciones tecnológicas de las sociedades formativas es la movilidad. Escola (2000) plantea que los grupos formativos accedieron a una amplia variedad de recursos líticos procedentes de los diversos microambientes integrados en su movilidad pastoril.

Ahora bien, avanzando un poco en el tiempo, con respecto a los estudios de los conjuntos líticos correspondientes al Tardío y Tardío-Inca microrregional podemos decir que su historia es breve (Escola et al. 1999, 2006 Ms; Elías et al. 2001; Olivera et al. 2003-2005; Elías 2005 Ms, 2005, 2006). A base de los resultados obtenidos hasta ahora, es interesante destacar que en la mayoría de los conjuntos analizados se ha observado en relación a aquellos formativos un incremento de la expeditividad en la producción de los instrumentos líticos, un uso mayoritario de materias primas muy próximas a los asentamientos y de una menor variedad de recursos, así como un aprovechamiento menor de las variedades de materias primas localizadas en el sector de quebradas altas (Elías et al. 2001; Elías 2006; Escola et al. 2006 Ms).

Hemos sugerido que estas tendencias estarían relacionadas con el incremento de la importancia de la agricultura en la economía de los grupos, lo que habría implicado la acentuación de los riesgos de mediano y largo plazo, y la importancia de los mecanismos buffer orientados a manejarlos, y con la disminución de la dinámica pastoril en provecho de la actividad agrícola y de una mayor fijación a la tierra (Elías 2005 Ms, 2006; Escola et al. 2006 Ms).

\section{Tecnología lítica en las sociedades posteriores a ca. 1000 años AP de Antofagasta de la Sierra: Algunos objetivos e hipótesis}

A continuación expondremos los objetivos generales y específicos, así como las hipótesis que guían nuestra investigación. Respecto a los dos primeros debemos aclarar que algunos de ellos superan los límites del presente artículo. Respecto a las hipótesis, constituyen propuestas a contrastar, con lo que nos referimos a que somos conscientes de que nuestros datos sólo permitirán la contrastación parcial de las mismas. Esperamos en el futuro poder continuar avanzando a partir de la obtención de mayor información.

Además de contribuir al conocimiento del proceso de cambio cultural de las sociedades en la cuenca de Antofagasta de la Sierra, a la comprensión de las sociedades tardías y tardías-incas ( $c a$. 1000-450 años AP) a partir del análisis de la evidencia lítica, y desde una perspectiva diacrónica, de las variaciones en la implementación de las estrategias tecnológicas líticas de éstas, con un fuerte componente agrícola en su subsistencia respecto de las del Formativo, predominantemente pastoriles que las precedieron (Escola 1996, 2000), queremos:

1) Acercarnos a las decisiones y estrategias involucradas en el aprovisionamiento, manufactura, uso, mantenimiento y descarte de los instrumentos líticos correspondientes a momentos posteriores a ca. 1000 años AP (Nelson 1991).

2) Evaluar la inversión de tiempo implicada en cada etapa del proceso de producción de distintos instrumentos.

3) Acercarnos a las decisiones de diseño que guiaron la manufactura de estos instrumentos líticos. 
4) Relevar la composición funcional de los conjuntos y la representación de instrumentos asociados a las actividades agrícolas.

5) Acercarnos a la comprensión del uso y aprovechamiento que las poblaciones tardías y tardías-incas hicieron de distintos recursos líticos.

6) Comparar, siempre que sea posible, los resultados obtenidos con aquellos alcanzados por Escola (2000) sobre el conjunto instrumental del sitio formativo de Casa Chávez Montículos 1 (CCHM1) con el fin de empezar a contribuir a una perspectiva diacrónica del cambio tecnológico.

Trabajamos con los siguientes supuestos:

1) En momentos tardíos y tardíos-incas en Antofagasta de la Sierra se profundizó la tendencia hacia la minimización del tiempo invertido en las distintas etapas implicadas en la producción de determinados instrumentos líticos, en función de la mayor importancia de las prácticas productivas en la subsistencia y de la necesidad de invertir más tiempo en otros mecanismos (sociales, tecnológicos, económicos) para dar respuesta a los riesgos. La ausencia de estrés temporal y el bajo costo de fracaso en la obtención de los recursos, que caracterizan a las sociedades que mantienen un estricto control sobre la ocurrencia de los mismos a través del manejo de su reproducción, influiría en las decisiones de diseño de los instrumentos. En el contexto de las sociedades agropastoriles de nuestro interés, la tecnología lítica estaría aún menos orientada a reducir el riesgo de pérdida de corto plazo de los recursos y la impredecibilidad en la obtención de los mismos.

1a) Gran parte de la tecnología lítica no estuvo principalmente orientada a obtener diseños confiables ni multifuncionales propicios, respectivamente, en situaciones de estrés temporal o de impredecibilidad en la obtención de los recursos, sino diseños utilitarios (Escola 2000) destinados a brindar soluciones adecuadas e inmediatas con escasa inversión de tiempo a lo largo de su producción y uso. Se caracterizarían por presentar soportes diversos, utilización poco selectiva de las materias primas, baja o nula formatización de sus filos, baja multifuncionalidad, escasas tareas de mantenimiento y reparación y corta vida útil (Escola 2000). En relación a la necesidad de invertir menos tiempo en la tecnología lítica y teniendo en cuenta la alta disponibilidad de materias primas en la región de interés (Aschero et al. 2002), consideramos que se habrían priorizado las materias primas "inmediatas", en referencia a materias primas cuyas fuentes se encuentran a menos de $5 \mathrm{~km}$ de distancia desde los sitios (Civalero y Franco 2003) y que involucrarían bajos costos de obtención.

1b)En función de la menor inversión de tiempo en el proceso de producción lítica se habría priorizado la inmediatez de las materias primas sobre la calidad y adecuación de las mismas para la confección de sus artefactos. Ahora bien, respecto a los instrumentos relacionados con las actividades agrícolas (palas y/o azadas, artefactos de molienda) postulamos que para momentos posteriores a $c a$. 1000 años AP estos instrumentos podrían mostrar diferencias en sus características tecnológicas y/o de representación en los conjuntos, respecto de aquellos en contextos formativos, en respuesta a la mayor importancia de las prácticas productivas en la subsistencia y la derivada necesidad de invertir más tiempo en otros mecanismos para dar respuesta a los riesgos de mediano y largo plazo asociados a ellas, así como al crecimiento poblacional.

A base de lo anterior, planteamos que:

2) En función de la mayor importancia de agricultura en la subsistencia, de la necesidad de invertir más tiempo en otros mecanismos para dar respuesta a los riesgos de mediano y largo plazo y del crecimiento poblacional, se habría incrementado la efectividad de los implementos asociados a la misma, así como su importancia en los conjuntos líticos. Esto podría evidenciarse en la presencia de palas y/o azadas con espesores más gruesos para acrecentar la resistencia a los golpes durante el uso y con pedúnculos más gruesos y fuertes (Nelson 1995). También, en la aplicación de distintas técnicas de manufactura en la obtención de los filos, como por ejemplo, alisado y pulido (Boydston 1989). Por su lado, los implementos de molienda podrían reflejar un incremento del largo de las manos, presencia de arreglos para facilitar su manejo y acrecentar la eficiencia, así como una mayor diversidad de ítems (p.e., manos realizadas con materias primas de distintos granos) (Parry y Christenson 1987; Nelson 1995; Babot 2004). 


\section{Los casos de estudio: La Alumbrera y Campo Cortaderas 1}

La Alumbrera (LA) es un gran sitio residencial localizado en el denominado fondo de cuenca, a unos 5-6 km al sur del poblado actual de Antofagasta de la Sierra (Figura 1). Son diversas las estructuras que conforman este asentamiento (recintos, tumbas), distribuidas sobre el bajo y el pie de monte de la ladera del volcán Antofagasta y a orillas de la laguna homónima. Las características arquitectónicas y la cerámica hallada en el sitio permiten asignarlo al Período de Desarrollos Regionales del Noroeste Argentino, con elementos que la relacionan estrechamente al sistema cultural Belén de los valles mesotermales de Abaucán y Hualfín y, más precisamente, a una etapa tardía de desarrollo del mismo (Raffino y Cigliano 1973; Olivera 1989, 1991). Asimismo, presenta rasgos arquitectónicos incaicos (troneras, vanos trapezoidales, imitación de sillería y recintos perimetrales compuestos o RPC) (Raffino y Cigliano 1973; Olivera 991), por lo que debió tener algún tipo de participación en el sistema inca en los Andes Centro Sur. Hasta el momento, sólo contamos con un fechado de $210 \pm 70 \mathrm{AP}$, obtenido sobre restos óseos humanos provenientes de una tumba colectiva (Olivera y Vigliani 2000-2002).

El material que estudiamos en este es producto de recolecciones superficiales llevadas a cabo en dos sectores del sitio, uno que denominamos "abra central" y otro que llamamos "cresta central", adyacente al anterior hacia el oeste. El primero presenta a lo largo de toda su extensión recintos de diversas formas (circulares, rectangulares/cuadrangulares), algunos de los cuales muestran aberturas bien construidas y escalinatas. Se halla orientado de sur a norte, abriéndose en su tramo final a la laguna de Antofagasta. En este sector se llevó a cabo una recolección de la superficie total, relevando el material cerámico y lítico. En la "cresta central" se realizaron recolecciones de superficie en cuatro recintos, y en el pasillo de circulación que corresponde al espacio entre los mismos, se recolectó la totalidad del material identificado.

Campo Cortaderas 1 se encuentra en el área arqueológica de Campo Cortaderas, ubicada unos $15 \mathrm{~km}$ al noroeste de la actual villa de Antofagasta de la Sierra en los sectores intermedios de la cuenca (Figura 1). La misma presenta recintos, terrazas, cuadros de cultivo y vestigios de una acequia o canal de riego prehispánico (Olivera et al. 2003-2005). Hemos identificado tres quebradas sucesivas con estructuras agrícolas y habitacionales: Campo Cortaderas 1 (CCT1), Campo Cortaderas 2 (CCT2) y Campo Cortaderas 3 (CCT3). Este asentamiento ha sido caracterizado como especializado en actividades agrícolas (Olivera et al. 2003-2005).

Respecto de la cronología de los sitios del área, aún no contamos con fechados absolutos. Sin embargo, presentan similitudes arquitectónicas con otros sitios tardíos de la microrregión, como Bajo del Coypar I (Sector 2) y Bajo del Coypar II. Asimismo, el material cerámico relevado evidencia tendencias similares a las observadas en La Alumbrera y en la ocupación final de Bajo del Coypar II (posterior a 670 años AP), con una importante representación de grupos Belén y Belén-Inca (Olivera et al. 2003-2005). Los materiales que estudiamos provienen de CCT1. En esta abra realizamos: a) una transecta con orientación noroeste-sureste atravesando diversas estructuras y campos, registrando in situ las características de los materiales y recolectando sólo algunos de ellos; b) recolecciones de superficie en un sector en el pie de monte bajo en la zona de campos de cultivo y en una serie de recintos superiores ubicados al noroeste del abra, recolectando en ambos casos todo el material cerámico como lítico; y c) un pequeño sondeo en un recinto cuadrangular contiguo al canal prehispánico.

En LA analizamos un total de 256 instrumentos líticos, relevados en el abra central y en los cuatro recintos de la cresta central. En tanto, en CCT1 consideramos un total de 98 instrumentos relevados en la zona de campos, en los recintos al noroeste del sitio y en la transecta referida.

\section{Metodología: Indicios de decisiones de diseño "utilitario" en los conjuntos instrumentales}

Para evaluar la "formalidad" e "informalidad" (Andrefsky 1994) o el carácter "utilitario" (sensu Escola 2000) de un instrumento seguimos a Escola (2000) en considerar que ello implica aproximarse a la inversión de tiempo en su manufactura y uso en función de: a) la obtención de las materias primas; b) las técnicas de reducción involucradas en la obtención de las formas bases; c) la evidencia de cierta estandarización de los soportes, tipos de hojas o lascas, tamaños o módulos; c) las técnicas de retoque en la formatización de los instrumentos; y d) la presencia de mantenimiento. Agregamos la "complejidad" (sensu Torrence 1983, 1989) que refiere al número de partes presentes en un instrumento. 
El análisis se realizó a nivel macroscópico, basándonos principalmente en la propuesta técnico-morfológica y morfológica-funcional de Aschero (1975 Ms, 1983 Ms), incorporando asimismo variables propuestas por otros investigadores como Koldehoff (1987), Parry y Kelly (1987) y Franco (2002). Consideramos que las siguientes variables técnico-morfológicas nos permiten evaluar la inversión de tiempo en la obtención de los instrumentos: materias primas, formas bases, tamaños relativos, módulos largoancho, espesores relativos, espesores de los bulbos en formas bases lascas (Parry y Kelly 1987), tipos de talones en el caso de las formas bases lascas, presencia o ausencia de preparación del frente de lascado (Escola 2000), series técnicas ${ }^{3}$, presencia de filos complementarios y porcentaje de corteza en las caras dorsales de las formas bases lascas (Franco 2002). El tipo de forma base, los tamaños, los módulos largo-ancho, los espesores, los tipos de talones y bulbos, los porcentajes de corteza y la preparación de los frentes de lascados en las formas bases lascas, nos brindaron información sobre las técnicas de reducción involucradas en la obtención de las mismas y las etapas de reducción de las que fueron producto, como medio de evaluar el esfuerzo invertido en la obtención de estos soportes. Las series técnicas son consideradas como indicadoras de la inversión de trabajo en los filos. La presencia de filos complementarios es considerada evidencia material de diseños multifuncionales. Se espera que estén representados en baja proporción ya que, generalmente, de acuerdo a la bibliografía, son consecuencias materiales de una estrategia conservada (Shott 1986; Nelson 1991).

Por otro lado, nos interesa acercarnos a la potencial composición funcional de los conjuntos recurriendo a las categorías de grupos y subgrupos tipológicos propuestos por Aschero (1975 Ms, 1983 Ms). La combinación de los mismos con las variables técnico-morfológicas ya mencionadas (formas bases, tamaños relativos, módulos largo-ancho, espesores y materias primas) nos posibilitó establecer si existe alguna diferencia en el tiempo invertido y en las decisiones tomadas en las distintas etapas de producción implicadas en la manufactura de diversos tipos.

Técnicas utilizadas en la obtención de los filos y la extensión de los lascados u otras técnicas sobre las caras o superficies de las piezas)
Respecto al análisis de palas y/o azadas, las variables que tomamos en cuenta son: materias primas utilizadas, formas bases, medidas absolutas de las piezas (espesor, largo y ancho), medidas absolutas de los pedúnculos y series técnicas (Nelson 1995; Pérez 2005 Ms).

En relación a los artefactos de molienda nos focalizaremos, principalmente, en su representación en los conjuntos ya que aún no contamos con resultados del análisis técnico-morfológico sistemático sobre los mismos.

\section{Los conjuntos instrumentales de LA y CCT1: Resultados y tendencias}

Entre los 256 instrumentos analizados de LA se identificaron 22 grupos tipológicos, siendo los denticulados y los artefactos de formatización sumaria los mayormente representados. Por su parte, en CCT1 (n=98) se identificaron 14 grupos tipológicos. Los más representados, al igual que en el sitio del fondo de cuenca, son los denticulados y los artefactos de formatización sumaria. En ambos conjuntos, es llamativa la escasa representación de palas y/o azadas líticas, así como de instrumentos que podrían estar relacionados a actividades de procesamiento de productos agrícolas. Nos interesa destacar que las primeras conforman el grupo tipológico con mayor frecuencia en el conjunto instrumental total de excavación del sitio formativo CCHM1 $(\mathrm{n}=510) .{ }^{4}$ Sin embargo, debemos señalar que en CCT1 dos ejemplares de palas y/o azadas se identificaron durante actividades de campo previas, y que si bien en el conjunto analizado procedente de este sitio no se han registrado manos, piedras de moler u otros tipos de instrumentos relacionados al procesamiento de granos, sí se han reconocido en el campo cuatro morteros in situ (Olivera et al. 2003-2005; Elías 2006) (Figura 2). En el caso particular de LA, es interesante señalar la presencia de perforadores, los cuales representan el $5.5 \%$ del conjunto. Por su parte, las puntas de proyectil se encuentran muy escasamente representadas en ambos sitios (Tabla 1).

A continuación desarrollaremos las tendencias relevadas en relación al uso de las materias primas

\footnotetext{
4 Corresponde a la muestra instrumental de excavación, sin considerar los núcleos, analizada por Escola (2000) procedente de CCHM1.
} 
líticas, la obtención y selección de las formas bases y la formatización de los filos.

\section{Aprovechamiento de recursos líticos}

En ambos conjuntos observamos un predominio de variedades de rocas no sólo "inmediatas", sino "muy inmediatas" (Elías 2006), cuyas fuentes se ubican a menos de $2 \mathrm{~km}$ de los sitios. En LA se trata de cuarcita, sobre la cual fue manufacturado el $72 \%$ del conjunto instrumental y más de la mitad de los grupos tipológicos identificados (Elías 2006). En CCT1 ( $n=98)$ un muy alto porcentaje de instrumentos $(82 \%)$ se encuentran manufacturados en vulcanita CCT. Asimismo, se seleccionó este recurso para la realización de 10 de los 14 grupos tipológicos identificados. La vulcanita CCT conforma una de las variedades de rocas identificadas en los afloramientos del área arqueológica de Campo Cortaderas, siendo "muy inmediata" (aprox. 400 m) a CCT1 (Olivera et al. 2003-2005; Elías 2005, 2006; Elías y Tchilinguirian 2006). Las restantes materias primas determinadas en el conjunto de este sitio muestran muy baja frecuencia (Tabla 2). Entre estas, y sólo refiriéndonos a aquellas de las que se han identificado fuentes, las vulcanitas 1,2 y 4 constituyen recursos locales (entre 5 y $40 \mathrm{~km}$ desde el sitio) (Civalero y Franco 2003). Las obsidianas representan las materias primas no locales (sensu Meltzer 1989), al ubicarse sus fuentes a más de 40 $\mathrm{km}$ de CCT1. Finalmente, la vulcanita 8 constituye una de las variedades de recursos líticos identificados en los afloramientos del área arqueológica de Campo Cortaderas (Olivera et al. 2003-2005; Elías 2005, 2006; Elías y Tchilinguirian 2006).

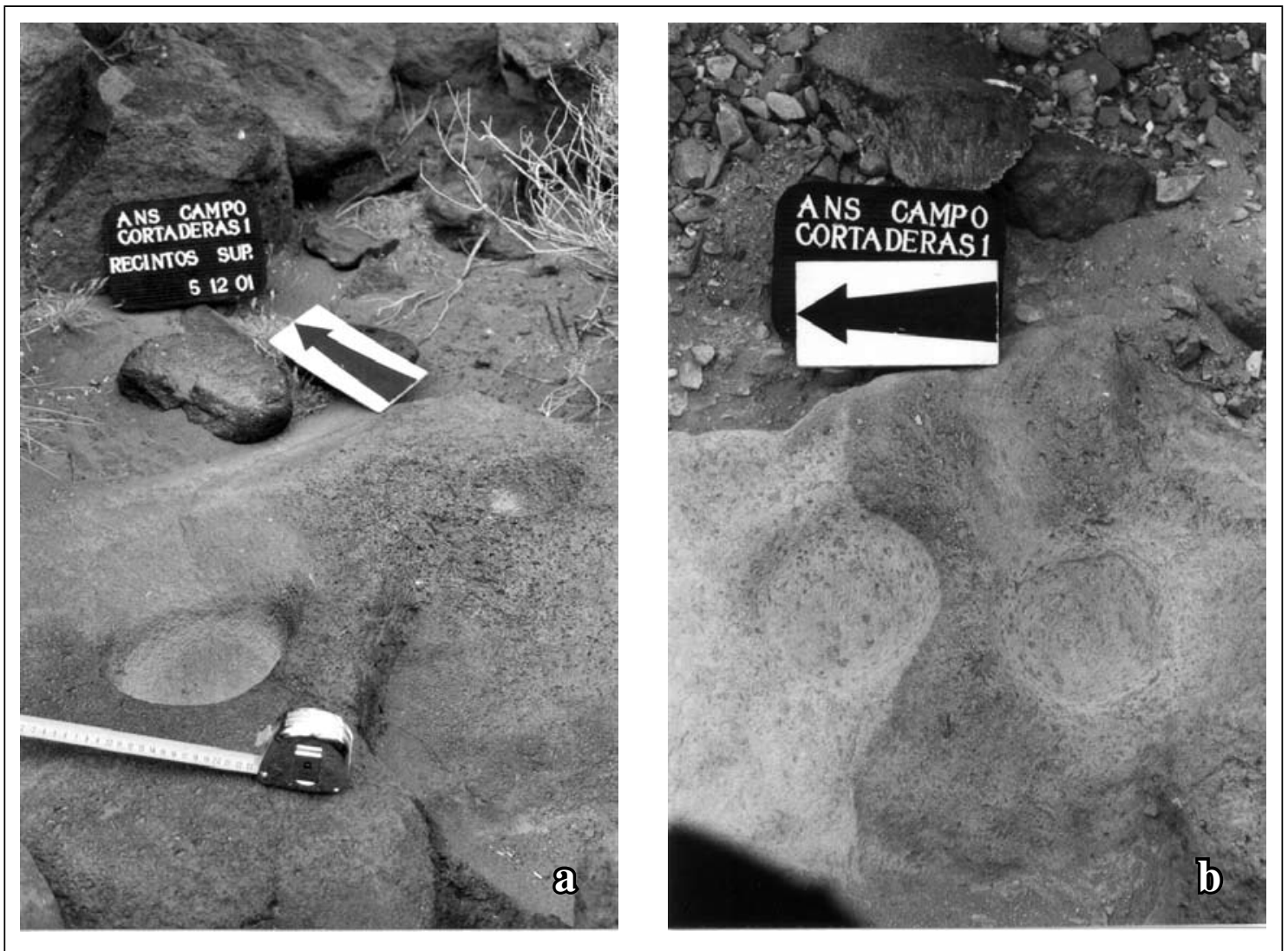

Figura 2. Morteros hallados in situ en Campo Cortaderas 1 en: a) uno de los recintos superiores; y b) cerca del canal de riego prehispánico. 


\begin{tabular}{|c|c|c|c|c|c|c|c|c|}
\hline \multirow{2}{*}{$\begin{array}{l}\text { Conjuntos } \\
\text { Grupos tipológicos }\end{array}$} & \multicolumn{2}{|c|}{ LA } & \multicolumn{2}{|c|}{ CCT1 } & \multicolumn{2}{|c|}{ CCHM1 $^{5}$} & \multicolumn{2}{|c|}{ CCHM1 $^{6}$} \\
\hline & $\mathbf{n}$ & $\%$ & $\mathbf{n}$ & $\%$ & $\mathbf{n}$ & $\%$ & n & $\%$ \\
\hline Denticulados & 68 & 26.6 & 26 & 28 & 10 & 2 & 8 & 2.9 \\
\hline Artefactos de formatización sumaria & 52 & 20.2 & 20 & 20 & 23 & 4.5 & 18 & 6.5 \\
\hline Raspadores & 23 & 9 & 4 & 4 & 10 & 2 & 10 & 3.6 \\
\hline Percutores & 21 & 8.2 & 1 & 1 & 18 & 3.5 & 15 & 5.6 \\
\hline Fragmentos no diferenciados de artefactos formatizados & 21 & 8.2 & 7 & 7 & 74 & 14.5 & 61 & 22.1 \\
\hline Muescas & 15 & 5.9 & 14 & 14 & 24 & 4.7 & 16 & 5.8 \\
\hline Perforadores & 14 & 5.5 & & & 3 & 0.6 & 2 & 0.7 \\
\hline Artefactos burilantes & 10 & 3.9 & 5 & 5 & 7 & 1.4 & 5 & 1.8 \\
\hline Puntas entre muescas & 7 & 2.7 & 1 & 1 & 2 & 0.4 & 2 & 0.7 \\
\hline Filos naturales con rastros complementarios (FNRC) & 6 & 2.2 & 8 & 8 & 40 & 7.7 & 37 & 13.4 \\
\hline Raederas & 5 & 2 & 4 & 4 & 27 & 5.3 & 18 & 6.5 \\
\hline $\begin{array}{l}\text { Artefactos mediano-pequeños/muy pequeños con retoque en bisel } \\
\text { oblicuo (RBO) }\end{array}$ & 3 & 1.2 & 2 & 2 & 13 & 2.5 & 12 & 4.3 \\
\hline Choppers & 2 & 0.8 & & & 2 & 0.4 & 2 & 0.7 \\
\hline Cortantes & 1 & 0.4 & & & 6 & 1.2 & 5 & 1.8 \\
\hline Instrumentos para picar & 1 & 0.4 & & & & & & \\
\hline Puntas de proyectil & 1 & 0.4 & 4 & 4 & \multirow{2}{*}{52} & \multirow{2}{*}{10.2} & \multirow{2}{*}{21} & \multirow{2}{*}{7.6} \\
\hline Preformas de puntas & 1 & 0.4 & & & & & & \\
\hline Puntas naturales con rastros complementarios & 1 & 0.4 & & & & & & \\
\hline Percutores s/lascas no formatizadas & 1 & 0.4 & & & & & & \\
\hline Palas y/o azadas & 1 & 0.4 & & & 151 & 29.6 & & \\
\hline Artefacto formatizado por picado, abrasión o pulido no diferenciado & 1 & 0.4 & 1 & 1 & & & & \\
\hline Manos & 1 & 0.4 & & & 3 & 0.6 & \multirow{2}{*}{6} & \multirow{2}{*}{2.2} \\
\hline Molinos & & & & & 5 & 1 & & \\
\hline Cuentas & & & 1 & 1 & & & & \\
\hline Litos no diferenciados modificados por uso & & & & & 22 & 4.3 & 21 & 7.6 \\
\hline Bifaces & & & & & 1 & 0.2 & 1 & 0.4 \\
\hline Grandes lascas con retoque & & & & & 9 & 1.8 & 8 & 2.9 \\
\hline Cuchillos de filo retocado & & & & & 2 & 0.4 & 2 & 0.7 \\
\hline Artefactos bisel asimétrico microretoque ultramarginal & & & & & 6 & 1.2 & 6 & 2.2 \\
\hline Totales & 256 & 100 & 98 & 100 & 510 & 100 & 276 & 100 \\
\hline
\end{tabular}

Tabla 1. Grupos tipológicos de instrumentos de LA, CCT1 y CCHM1 (Escola 2000: 268-69).

Lo señalado en los párrafos precedentes se aleja de lo que ocurre en el sitio formativo de CCHM1, donde los recursos líticos locales (vulcanitas 4 , 2, 6 y $7^{7}$ y el ópalo) conforman el $57.3 \%$ de la

5 Corresponde al total de instrumentos, sin considerar los núcleos, relevados en las excavaciones de CCHM1 (Escola 2000). La presentación de estos datos se debe a la necesidad de incorporar las palas y/o azadas, las cuales no fueron consideradas por Escola en la muestra de instrumentos analizada, ya que las trató separadamente en su tesis.

6 Corresponde a la muestra instrumental de excavación, sin considerar los núcleos, analizada por Escola (2000) procedente de CCHM1.

7 Para una descripción detallada de las distintas vulcanitas y su origen espacial ver Aschero y colaboradores (2002) y Elías y Tchilinguirian (2006) para la vulcanita CCT. muestra, alcanzando aquellos "muy inmediatos" (cuarcita y arenisca) limitada presencia. No debemos obviar dentro del primer grupo a la vulcanita 8 (Escola 2000; Elías y Escola 2006 Ms) (Tabla 2).

\section{Adquiriendo los soportes}

En LA $(n=256)$ predominan las formas bases lascas. Las restantes formas bases identificadas son formas bases no diferenciadas, guijarros, nódulos no diferenciados, lajas, núcleos sin pátina diferencial y clastos angulosos naturales transportables. En lo que hace a las lascas, predominan las angulares, seguidas de las no diferenciadas, las primarias y 


\begin{tabular}{|c|c|c|c|c|c|c|c|c|}
\hline \multirow{2}{*}{$\begin{array}{l}\text { Conjuntos } \\
\text { Materias primas } \\
\end{array}$} & \multicolumn{2}{|l|}{ LA } & \multicolumn{2}{|c|}{ CCT1 } & \multicolumn{2}{|c|}{$\mathrm{CCHM1}^{8}$} & \multicolumn{2}{|c|}{ CCHM1 $^{9}$} \\
\hline & $\mathbf{n}$ & $\%$ & $\mathbf{n}$ & $\%$ & $\mathbf{n}$ & $\%$ & $\mathbf{n}$ & $\%$ \\
\hline Cuarcita & 184 & 72 & 0 & 0 & 17 & 6.2 & 23 & 4.5 \\
\hline Obsidianas & 13 & 5 & 5 & 5 & 63 & 22.8 & 105 & 20.1 \\
\hline Vulcanita 4 & 11 & 4.3 & 1 & 1 & 107 & 38.8 & \multirow{4}{*}{189} & \multirow{4}{*}{37} \\
\hline Vulcanita 2 & 8 & 3.1 & 1 & 1 & 11 & 4 & & \\
\hline Vulcanita 7 & & & & & 33 & 12 & & \\
\hline Vulcanita 6 & & & & & 4 & 1.4 & & \\
\hline Vulcanita 8 & 9 & 3.5 & 5 & 5 & & & 151 & 29.6 \\
\hline Vulcanita 1 & 6 & 2.4 & 2 & 2 & & & & \\
\hline Opalo & 4 & 1.6 & & & 3 & 1.1 & \multirow{3}{*}{6} & \multirow{3}{*}{1.8} \\
\hline Calcedonia & 13 & 5.1 & & & 2 & 0.7 & & \\
\hline Sílice & & & 1 & 1 & 1 & 0.4 & & \\
\hline Vulcanita CCT & 3 & 1.2 & 80 & 82 & & & & \\
\hline Cuarzo & 3 & 1.2 & & & & & & \\
\hline Vulcanita no diferenciada & 1 & 0.3 & & & & & & \\
\hline Vidrio volcánico 2 & 1 & 0.3 & & & & & & \\
\hline Granito & & & 1 & 1 & & & & \\
\hline Materia prima verdosa no diferenciada & & & 1 & 1 & & & & \\
\hline Arenisca & & & & & 12 & 4.3 & & \\
\hline $\begin{array}{l}\text { Basalto vesicular, pórfidos volcánicos y materias primas } \\
\text { no determinadas }\end{array}$ & & & 1 & 1 & 23 & 8.3 & 36 & 7 \\
\hline Totales & 256 & 100 & 98 & 100 & 276 & 100 & 510 & 100 \\
\hline
\end{tabular}

Tabla 2. Materias primas de instrumentos de LA, CCT1 y CCHM1 (Escola 2000: 268-69).

\begin{tabular}{|c|c|c|c|c|c|c|}
\hline \multirow{2}{*}{$\begin{array}{l}\text { Conjuntos } \\
\text { Formas bases }\end{array}$} & \multicolumn{2}{|c|}{ LA } & \multicolumn{2}{|c|}{ CCT1 } & \multicolumn{2}{|c|}{ CCHM1 $^{8}$} \\
\hline & $\mathbf{n}$ & $\%$ & $\mathbf{n}$ & $\%$ & $\mathbf{n}$ & $\%$ \\
\hline Guijarro de sección circular, oval o elíptica & 8 & 3.1 & & & 10 & 3.6 \\
\hline Guijarro de sección elíptica alargada o chato & 1 & 0.4 & & & 13 & 4.7 \\
\hline Guijarro de sección plano-convexa & 2 & 0.8 & & & 4 & 1.5 \\
\hline Hemiguijarro natural & 3 & 1.2 & & & 2 & 0.7 \\
\hline Laja & 5 & 1.9 & 3 & 3 & 2 & 0.7 \\
\hline Clasto o fragmento anguloso natural & 2 & 0.8 & 2 & 2 & 10 & 3.6 \\
\hline Nódulo tabular & & & & & 5 & 1.8 \\
\hline Nódulo no diferenciado & 6 & 2.3 & 1 & 1 & 2 & 0.7 \\
\hline Lasca primaria & 34 & 13.2 & 3 & 3 & 8 & 2.9 \\
\hline Lasca secundaria & 26 & 10.2 & 5 & 5 & 21 & 7.6 \\
\hline Lasca con dorso natural & 3 & 1.2 & & & 1 & 0.5 \\
\hline Lasca angular & 75 & 29.3 & 48 & 49 & 28 & 10.1 \\
\hline Lasca de arista & 1 & 0.4 & 1 & 1 & 2 & 0.7 \\
\hline Lasca plana & 1 & 0.4 & 3 & 3 & 3 & 1.1 \\
\hline Lasca de flanco de núcleo & & & & & 2 & 0.7 \\
\hline Lasca no diferenciada & 67 & 26.2 & 25 & 26 & 44 & 15.9 \\
\hline Núcleo con pátina diferenciada & & & & & 2 & 0.7 \\
\hline Núcleo sin pátina diferenciada & 4 & 1.6 & & & 1 & 0.5 \\
\hline Forma base no diferenciada & 18 & 7 & 7 & 7 & 116 & 42 \\
\hline Totales & 256 & 100 & 98 & 100 & 276 & 100 \\
\hline
\end{tabular}

Tabla 3. Formas bases de instrumentos de LA, CCT1 y CCHM1.

8 Corresponde a la muestra instrumental de excavación, sin considerar los núcleos, analizada por Escola (2000) procedente de CCHM1.
9 Corresponde a la muestra instrumental de excavación, sin considerar los núcleos, analizada por Escola (2000) procedente de CCHM1. 
las secundarias. ${ }^{10} \mathrm{La}$ alta representación de lascas no diferenciadas se debe a que consideramos dificultoso adscribirlas a alguna categoría cuando se hallaban fracturadas (Tabla 3).

Entre las formas bases lascas de LA $(n=178$, sin fracturadas longitudinal y transversalmente) observamos un predominio de tamaños muy grandes, seguidos de los grandes y medianos grandes. Entre los módulos largo-ancho de estos soportes, sin tomar en cuenta aquellas fracturadas $(n=110)$, los laminares se hallan escasamente representados, predominando los cortos anchos y los medianos normales. En tanto, entre sus espesores relativos sobresalen los gruesos y los muy gruesos. Ahora bien, los talones ( $n=127$, tomando en cuenta sólo los enteros o parcialmente fracturados), evidencian una tendencia hacia el predominio de lisos, seguidos de los naturales (corticales), los diedros y los no diferenciados. En lo referente a la regularización de los frentes de lascado $(n=127)$, observamos una alta frecuencia de no regularizados. Entre los bulbos $(n=207)$, predominan los espesores gruesos y muy gruesos. Los no pertinentes corresponden a lascas que no presentan bulbos, ya sea por encontrarse fracturadas o por haber sido eliminados por lascados directos o inversos. Finalmente, respecto a los valores de corteza entre las formas bases lascas de instrumentos enteros ( $\mathrm{n}=110$, sin fracturadas), predominan las que presentan valores de $100 \%$, seguidas por aquellas con $25 \%$ y $75 \%$ (Tabla 4 ).

En la muestra procedente de CCT1 (n=98) las formas bases mayormente representadas son las lascas, predominando entre estas las angulares, seguidas de las no diferenciadas. Las primarias y secundarias representan conjuntamente el $8 \%$ de la muestra. En este sentido el conjunto de CCT1 se aleja visiblemente del de LA, donde estas últimas se hallan en mayor proporción (Tabla 3).

10 En las definiciones de los tipos de lascas seguimos la propuesta formulada en el I Taller "Morfología Macroscópica en la Clasificación de Artefactos Líticos: Innovaciones y Perspectivas" (22 al 25 de junio de 2004, San Miguel de Tucumán, Argentina): una lasca primaria presenta toda la cara dorsal cubierta con corteza, y una lasca secundaria presenta un solo negativo de lascado, cualquiera sea su tamaño, sobre la cara dorsal y el resto cubierto de corteza; en una lasca angular, los negativos de extracciones anteriores provienen de diferentes direcciones (no paralelas) y puede presentar reserva de corteza.
Entre los soportes lascas $(n=72$, sin fracturadas longitudinal y transversalmente) sobresalen, como en LA, los tamaños muy grandes, seguidos de los grandes y medianos grandes. Entre los módulos largo-ancho ( $\mathrm{n}=36$, sin fracturadas) los medianos normales conforman los más representados, seguidos de los cortos muy anchos y los cortos anchos. Los módulos laminares encuentran limitada presencia. Entre los espesores relativos de las formas bases lascas sobresalen los gruesos, seguidos de los muy gruesos. Respecto de los talones, en el caso de los ejemplares con talones enteros o parcialmente fracturados $(n=50)$, observamos un predominio de talones lisos, seguidos de los diedros, naturales (corticales) y lisos naturales (corticales). En lo que hace a la regularización de los frentes de extracción prevalecen, al igual que en LA, los no regularizados, aunque los regularizados se encuentran mejor representados que en el sitio del fondo de cuenca. Finalmente, entre los bulbos $(\mathrm{n}=85)$ observamos un predominio de espesores gruesos, seguidos de los delgados. En relación a los porcentajes de corteza sobre las caras dorsales de los soportes lascas ( $n=36$, sin fracturadas) predominan aquellas sin corteza, seguidas por las que presentan 25\% (Tabla 4).

Sintetizando, sugerimos que en ambos sitios una alta frecuencia de formas bases lascas no fue producto de etapas avanzadas de reducción. Esto se evidencia en el predominio de tamaños muy grandes, bulbos gruesos y muy gruesos, caras dorsales con reserva de corteza y talones lisos. Si bien estos últimos forman parte de la categoría de talones preparados, sobresalen rotundamente, quedando los diedros y facetados escasamente representados.

Ahora bien, al comparar el conjunto de formas bases lascas de CCT1 con el de LA, el primero sugiere haber sido producto de etapas más avanzadas de reducción. Esto se observa en la mayor representación de talones diedros, bulbos delgados y formas bases lascas sin corteza en sus caras dorsales. Sin embargo, no debemos perder de vista que los tamaños muy grandes, los espesores gruesos y muy gruesos de las piezas, los bulbos gruesos y los talones lisos siguen sobresaliendo.

Debemos mencionar que estas tendencias se acentúan en el caso de la cuarcita en LA y la vulcanita CCT en CCT1. Los instrumentos en obsidianas, calcedonia y ópalo se aíslan de las directrices señaladas para ambos conjuntos. Entre estos últimos recursos, registramos casi exclusivamente tamaños 


\begin{tabular}{|c|c|c|c|c|c|}
\hline & & \multicolumn{2}{|c|}{$\begin{array}{c}\text { LA } \\
(n=256)\end{array}$} & \multicolumn{2}{|c|}{$\begin{array}{l}\mathrm{CCT1} \\
(\mathrm{n}=98)\end{array}$} \\
\hline & & $n$ & $\%$ & $n$ & $\%$ \\
\hline \multirow{6}{*}{$\begin{array}{c}\text { Tamaños relativos } \\
\text { (s/fracturadas longitudinal } \\
\text { y transversalmente) }\end{array}$} & Pequeñas & 11 & 6 & 3 & 4 \\
\hline & Medianas pequeñas & 10 & 6 & 5 & 7 \\
\hline & Medianas grandes & 32 & 18 & 7 & 10 \\
\hline & Grandes & 44 & 25 & 17 & 24 \\
\hline & Muy grandes & 81 & 45 & 40 & 55 \\
\hline & Totales & 178 & 100 & 72 & 100 \\
\hline \multirow{7}{*}{$\begin{array}{l}\text { Módulos largo-ancho } \\
\text { (sin fracturadas) }\end{array}$} & Laminares normales & 5 & 5 & 2 & 6 \\
\hline & Medianas alargadas & 3 & 3 & 4 & 11 \\
\hline & Medianas normales & 42 & 38 & 15 & 41 \\
\hline & Cortas anchas & 50 & 45 & 5 & 14 \\
\hline & Cortas muy anchas & 7 & 6 & 8 & 22 \\
\hline & Cortas anchísimas & 3 & 3 & 2 & 6 \\
\hline & Totales & 110 & 100 & 36 & 100 \\
\hline \multirow{5}{*}{ Espesores relativos } & Muy delgadas (menor $5 \mathrm{~mm}$ ) & 8 & 4 & 6 & 7 \\
\hline & Delgadas $(5.1$ a $10 \mathrm{~mm})$ & 35 & 17 & 10 & 12 \\
\hline & Gruesas (10.1 a $20 \mathrm{~mm})$ & 106 & 51 & 52 & 61 \\
\hline & Muy gruesas (20.1 a $40 \mathrm{~mm})$ & 58 & 28 & 17 & 20 \\
\hline & Totales & 207 & 100 & 85 & 100 \\
\hline \multirow{9}{*}{$\begin{array}{c}\text { Tipo de talones } \\
\text { (enteros o parcialmente } \\
\text { fracturados) }\end{array}$} & Naturales (corticales) & 25 & 20 & 4 & 8 \\
\hline & Lisos-naturales (corticales) & 7 & 6 & 3 & 6 \\
\hline & Lisos & 67 & 52 & 26 & 52 \\
\hline & Diedros & 9 & 7 & 11 & 22 \\
\hline & Facetados & 5 & 4 & 1 & 2 \\
\hline & Filiforme & 1 & 1 & & \\
\hline & Astillado & 3 & 2 & 1 & 2 \\
\hline & No diferenciados & 10 & 8 & 4 & 8 \\
\hline & Totales & 127 & 100 & 50 & 100 \\
\hline \multirow{5}{*}{$\begin{array}{l}\text { Regularización de } \\
\text { frentes de lascado }\end{array}$} & No regularizados & 117 & 92 & 39 & 78 \\
\hline & Regularizados & 6 & 5 & 10 & 20 \\
\hline & Con rastros aislados de regularización & & & 1 & 2 \\
\hline & No diferenciados & 4 & 3 & & \\
\hline & Totales & 127 & 100 & 50 & 100 \\
\hline \multirow{7}{*}{$\begin{array}{l}\text { Espesores relativos } \\
\text { de los bulbos }\end{array}$} & Muy delgados (menor $5 \mathrm{~mm}$ ) & 1 & 0.5 & 1 & 1 \\
\hline & Delgados $(5.1 \mathrm{a} 10 \mathrm{~mm})$ & 14 & 6.7 & 10 & 12 \\
\hline & Gruesos (10.1 a $20 \mathrm{~mm})$ & 73 & 35.3 & 32 & 38 \\
\hline & Muy gruesos $(20.1 \mathrm{a} 40 \mathrm{~mm})$ & 41 & 19.8 & 5 & 6 \\
\hline & No diferenciados & 19 & 9.2 & 7 & 8 \\
\hline & No pertinente & 59 & 28.5 & 30 & 35 \\
\hline & Totales & 207 & 100 & 85 & 100 \\
\hline \multirow{7}{*}{ Corteza } & $0 \%$ & 15 & 14 & 14 & 39 \\
\hline & $25 \%(0.1-25 \%)$ & 27 & 24 & 12 & 33 \\
\hline & $50 \%(25.1-50 \%)$ & 14 & 13 & 4 & 11 \\
\hline & $75 \%(50.1-75 \%)$ & 24 & 22 & 3 & 8 \\
\hline & $100 \%(75.1-100 \%)$ & 29 & 26 & 3 & 9 \\
\hline & No diferenciada & 1 & 1 & & \\
\hline & Totales & 110 & 100 & 36 & 100 \\
\hline
\end{tabular}

Tabla 4. Propiedades de las formas bases lascas de instrumentos de LA y CCT1. 
pequeños y medianos pequeños, espesores delgados y muy delgados, bulbos delgados y muy delgados y superficies de corteza inferiores a 25\%. En el resto de las materias primas representadas se observa mayor diversidad entre estas variables (Elías 2006).

Finalmente, nos interesa destacar que la casi ausencia de frentes de lascados regularizados y la casi nula presencia de productos bifaciales y de módulos laminares nos llevan a plantear que limitado tiempo fue invertido en la obtención de estos soportes y que no fueron productos de técnicas estandarizadas de extracción. No debemos dejar de considerar las restantes formas bases (nódulos, lajas, guijarros, clastos angulosos), las cuales, asimismo, requirieron escasa inversión de tiempo en su obtención.

Ahora compararemos los resultados obtenidos sobre el conjunto de formas bases de instrumentos de LA y CCT1 con aquellos alcanzados por Escola (2000) para el conjunto instrumental lítico del sitio formativo de CCHM1. Deseamos aclarar que en la comparación de las formas bases de los conjuntos instrumentales de los tres sitios actualmente sólo consideramos los tipos de formas bases, los tipos de lascas y los tamaños relativos de los instrumentos, variables disponibles en Escola (2000). Esta autora, dados sus intereses, no consideró aisladamente en la exposición de los datos las formas bases lascas de los instrumentos de CCHM1 y algunas variables consideradas por nosotros (p.e., porcentaje de corteza, regularización, etc.), por lo que se tornó dificultosa la comparación con los resultados obtenidos sobre las mismas en los conjuntos instrumentales de LA y CCT1. Más allá de esto existen algunas diferencias que consideramos importante señalar, aunque futuros análisis serán necesarios sobre este conjunto instrumental formativo o sobre otra muestra asignable a estos momentos con el fin de evaluar las hipótesis propuestas.

Entre las formas bases de instrumentos de CCHM1 $(n=276)$ (Escola 2000: 270) se observa un predominio de lascas $(39.5 \%)$, seguidas de guijarros $(10.5 \%)$, nódulos $(2.5 \%)$, clastos $(3.6 \%)$, lajas $(0.7 \%)$ y algunos fragmentos de núcleos utilizados como alternativas de soporte (1.2\%). Escola (2000: 270-271) señala la preeminencia de formas bases no diferenciadas $(42 \%)(\mathrm{n}=276$, sin tomar en cuenta núcleos), lo cual, dice la autora, puede deberse al alto grado de fragmentación de las piezas y, destacamos, a la presencia de instrumentos con retoque extendido. Asimismo, entre las formas bases lascas predominan las no diferenciadas (15.9\%), seguidas de las internas $(12.7 \%)$ y las externas $(10.9 \%)$ $(n=276)$ (Escola 2000: 270-271). Observamos, entonces, que el conjunto instrumental de CCHM1 se aleja de aquellos de LA y CCT1 por la alta representación de formas bases no diferenciadas y lascas no diferenciadas, lo que no observamos en estos dos últimos sitios.

Ahora bien, tanto en LA como en CCHM1 las lascas externas no conforman los soportes mayormente representados, sin embargo, en el primer sitio muestran superior frecuencia (23.4\%) que en el segundo. Por otro lado, en CCT1 las lascas externas se hallan representadas en menor proporción que en CCHM $1(10.9 \%)$.

Respecto de los tamaños relativos, entre los artefactos formatizados en CCHM1, sobre un total de 65 ítems enteros o con fracturas irrelevantes (Escola 2000: 273), predominan los tamaños medianos pequeños $(30.8 \%)$, pequeños $(20 \%)$ y los muy grandes $(20 \%)$, seguidos de los grandes (15.4\%) y medianos grandes (13.8\%). En el caso de los artefactos no formatizados, tomando sólo las piezas enteras o con fracturas irrelevantes (n=52), Escola (2000: 149) señala el predominio de tamaños muy grandes $(55.7 \%)$ y grandes $(21.2 \%)$, y en menor medida, de tamaños medianos grandes $(13.5 \%)$ y medianos pequeños $(9.6 \%)$. Debemos destacar que entre los artefactos no formatizados las formas bases de gran tamaño como guijarros, nódulos, clastos y lajas son las principalmente representadas (Escola 2000: 151). Entonces, si bien en CCHM1 los tamaños muy grandes se encuentran bien representados, en LA y CCT1 hallan mayor representación. En el primer sitio, aproximadamente, representan el $36 \%$ del total de piezas enteras o con fracturas irrelevantes $(\mathrm{n}=117)$, siendo las formas bases como guijarros, nódulos, clastos y lajas los mayormente representados. ${ }^{11}$ En el segundo, si tomamos en cuenta los no pertinentes, no medidos debido a sus tamaños demasiado grandes, la representación de tamaños muy grandes asciende al $48 \%(\mathrm{n}=220$, sin fracturados longitudinal y transversalmente) (Elías 2006). Por su parte, en CCT1 el 58\% de los instrumentos ( $\mathrm{n}=81$, sin fracturados longitudinal y transversalmente) presentan tamaños muy grandes, habiendo sido

11 Dado que Escola (2000) presenta los tamaños discriminados en artefactos formatizados y no formatizados, nos vimos obligados a hacer un cálculo aproximado de la representación de los mismos en el conjunto. 
manufacturados gran parte de los mismos sobre formas bases lascas.

Sugerimos, entonces, que en LA y CCT1 las formas bases e instrumentos fueron productos y objetos de menor reducción que en CCHM1. Sin embargo, volvemos a repetir, que futuros análisis son necesarios.

\section{Selección de los soportes}

Como dijimos, una forma de evaluar la inversión de tiempo en la obtención de los instrumentos de un conjunto es registrar la evidencia de cierta estandarización en los soportes (tipos de hojas o lascas, tamaños o módulos) (Escola 2000). En este sentido nos interesó explorar si observamos homogeneidad entre las materias primas y características de los soportes utilizados en la manufactura de los distintos grupos tipológicos identificados en ambos conjuntos.

Materias primas y grupos tipológicos. En LA, como mencionamos, más de la mitad de los grupos tipológicos identificados se encuentran manufacturados en cuarcita. Entre estos sólo algunos fueron realizados exclusivamente sobre este recurso lítico. Es el caso de los percutores que se hallan sobre guijarros de esta roca, las raederas y los filos naturales con rastros complementarios (en adelante FNRC). Entre otros grupos tipológicos, si bien la cuarcita sigue conformando la roca con mayor frecuencia, también, otros recursos líticos hallan representación. Ocurre entre los raspadores, muescas, denticulados, puntas entre muescas, artefactos burilantes, artefactos de formatización sumaria y fragmentos no diferenciados de artefactos formatizados. Tres artefactos medianos-pequeños/muy pequeños con retoque en bisel oblicuo (en adelante $\mathrm{RBO}$ ), un cortante, instrumentos para picar, una punta natural con rastros complementarios, un fragmento de pala y/o azada, un artefacto formatizado por picado, abrasión o pulido, los únicos dos ejemplares de puntas de proyectil registrados y los perforadores no se encuentran realizados en cuarcita. El fragmento de pala y/o azada lo hallamos en vulcanita 8 , los tres RBO se encuentran en calcedonia y los únicos dos ejemplares de puntas de proyectil registrados fueron manufacturados sobre las dos variedades de obsidianas identificadas en el conjunto. Finalmente, en los perforadores predomina la calcedonia, seguida del ópalo (Gráfico 1).
Proponemos entonces que sólo para la manufactura de algunos grupos tipológicos fueron seleccionadas materias primas con características específicas. Se destacan entre estos los perforadores y RBO realizados exclusivamente en rocas de textura fina (calcedonia, ópalo, vulcanita 2 , vidrio volcánico 2 y obsidiana 1). Asimismo, los percutores fueron manufacturados únicamente sobre cuarcita. Probablemente, la forma de guijarros en que se halla esta roca jugó un rol importante en su elección. Por último, no debemos dejar de mencionar las puntas de proyectil realizadas exclusivamente en obsidiana.

En CCT1 observamos similares tendencias que en el conjunto del fondo de cuenca. Si bien la vulcanita CCT fue elegida para la realización de gran parte de los grupos tipológicos, algunos no fueron realizados sobre este recurso. Dentro de este grupo se destacan nuevamente los RBO sobre materias primas de textura fina y las puntas de proyectil en obsidiana. La vulcanita CCT predomina entre los raspadores, muescas, denticulados, artefactos burilantes, FNRC y artefactos de formatización sumaria. Asimismo, como ocurre en LA, entre algunos de estos grupos tipológicos otros recursos líticos hallan representación, aunque en mucha menor frecuencia que en el sitio residencial (Gráfico 2).

Formas bases y grupos tipológicos. Respecto de las formas bases sobre las que fueron manufacturados los distintos grupos tipológicos, sólo los percutores, el fragmento de mano, los choppers, instrumentos para picar, el fragmento de pala y/o azada, el artefacto formatizado por picado, abrasión o pulido no fueron fabricados sobre formas bases lascas en el conjunto de LA. Los percutores fueron realizados, principalmente, sobre guijarros, nódulos no diferenciados y núcleos sin pátina diferencial que, también, se emplearon en la obtención del fragmento de mano y los dos choppers. Asimismo, sobre estas formas bases se realizaron un raspador y un denticulado. En cuanto a las lajas, como ya mencionamos, hemos identificado un fragmento de filo de una pala y/o azada. Sin embargo, otros grupos tipológicos se hallan realizados en esta forma base: una punta entre muescas, un artefacto de formatización sumaria y dos fragmentos no diferenciados de artefactos formatizados. Entre las formas bases no diferenciadas encontramos, primordialmente, perforadores (Gráfico 3).

Por otro lado, si bien en la manufactura de raspadores, denticulados, puntas entre muescas y artefactos de formatización sumaria se recurrió, principalmente, 
a las formas bases lascas, también se hizo uso, en muy baja frecuencia, de otros soportes.

Ahora, con relación a los tamaños de los instrumentos, en primer lugar, debemos decir que en el conjunto predominan los tamaños muy grandes, seguidos de los grandes y medianos grandes. Los percutores se hallan principalmente realizados sobre tamaños muy grandes y no pertinentes. Por el contrario, entre los perforadores y las puntas de proyectil los tamaños pequeños predominan, acompañados de los muy pequeños y medianos pequeños. Estos ítems no fueron manufacturados sobre tamaños ni medianos grandes, grandes o muy grandes. Finalmente, raspadores, muescas, denticulados, puntas entre muescas, artefactos burilantes, FNRC, artefactos de formatización sumaria y fragmentos no diferenciados de artefactos formatizados, los hallamos representados en diversos tamaños, aunque, los grandes y muy grandes siguen predominando en la mayoría de estos grupos tipológicos (Gráfico 5).

Respecto de los módulos largo-ancho, entre los perforadores se concentran los laminares normales y medianos alargados. Por su parte, los dos ejemplares de puntas de proyectil presentan módulos medianos normales. Raspadores, denticulados, puntas entre muescas, artefactos burilantes y artefactos de formatización sumaria se hallan sobre formas bases con módulos largo-ancho diversos, aunque, con predominio de los medianos normales y cortos anchos (Gráfico 7).

Con relación a los espesores relativos, entre los percutores los gruesísimos son dominantes. No así en los perforadores, entre los que sólo se encuentran representados espesores muy delgados y delgados, al igual que entre los escasos ejemplares de puntas de proyectil y RBO. Por su lado, raspadores, raederas, muescas, denticulados, puntas entre muescas, artefactos burilantes, FNRC y artefactos de formatización sumaria se hallan realizados sobre formas bases de diversos espesores, aunque con predominio de los gruesos y muy gruesos (Gráfico 9).

Ahora bien, en CCT1, 11 de los grupos tipológicos identificados fueron realizados sobre soportes lascas. Una cuenta, el artefacto formatizado por picado abrasión o pulido no diferenciado y un percutor no se hallan en estos soportes. Al igual que en LA, en la manufactura de algunos tipos instrumentales se recurrió, aunque en baja frecuencia, a otros soportes además de lascas. Esto ocurre entre las muescas, los denticulados, artefactos de formatización sumaria y fragmentos no diferenciados de artefactos formatizados (Gráfico 4).

Al discriminar tamaños por grupos tipológicos observamos que, aunque entre los denticulados, FNRC, artefactos de formatización sumaria y fragmentos no diferenciados de artefactos formatizados predominan los muy grandes y grandes, también, se encuentran manufacturados sobre soportes con otras dimensiones. Los raspadores y artefactos burilantes se hallan realizados sobre soportes muy grandes y medianos grandes. Las muescas sobre soportes grandes y muy grandes y las raederas sobre soportes muy grandes. Entre las puntas de proyectil, al igual que en LA, los tamaños pequeños predominan (Gráfico 6)

En cuanto a los módulos largo-ancho, los raspadores, denticulados y artefactos de formatización sumaria fueron realizados sobre formas bases con diversos módulos, si bien predominan los medianos normales y cortos anchos. Por su lado, las puntas de proyectil muestran sólo módulos laminares normales y medianos alargados (Gráfico 8).

Finalmente, en lo que refiere a los espesores relativos de los instrumentos, si bien entre las muescas, los denticulados, FNRC, artefactos de formatización sumaria y fragmentos no diferenciados de artefactos formatizados predominan los espesores gruesos seguidos de los muy gruesos, también, formas bases de otros grosores fueron registradas. Como en LA, las puntas de proyectil registran sólo espesores muy delgados y delgados. Asimismo, los únicos dos ejemplares de RBO identificados se ubican dentro de estas categorías (Gráfico 10).

Sintetizando, en ambos conjuntos sólo los percutores, perforadores, puntas de proyectil y RBO muestran evidencias de selección de formas bases específicas para su manufactura.

Los raspadores, raederas, muescas, denticulados, puntas entre muescas, artefactos burilantes, artefactos de formatización sumaria y FNRC, por un lado, al compararlos entre sí, evidencian una llamativa homogeneidad entre sus soportes. Por otro, al interior de cada tipo, si bien siguen predominando las tendencias observadas en el conjunto, revelan, también, mayor diversidad. Sugerimos, entonces, que la manufactura de estos grupos tipológicos exigió menos especificidad en la selección de los soportes y sus características. 


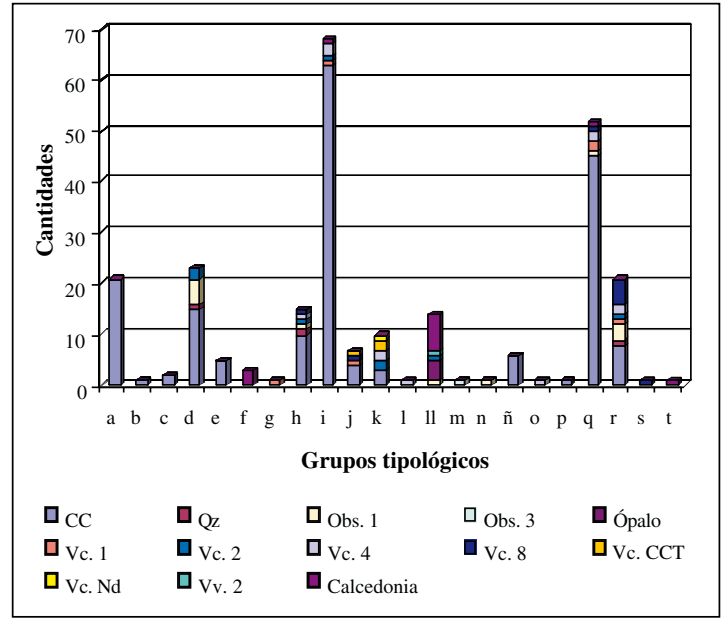

Gráfico 1. Materias primas por grupos tipológicos en La Alumbrera. Instrumentos $(\mathrm{n}=256)$;

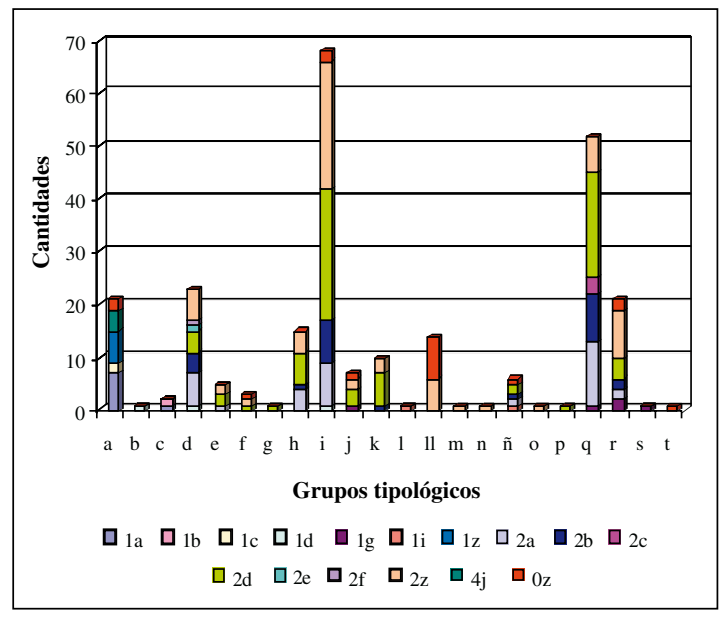

Gráfico 3. Formas bases por grupos tipológicos en La Alumbrera. Instrumentos ( $\mathrm{n}=256)$.

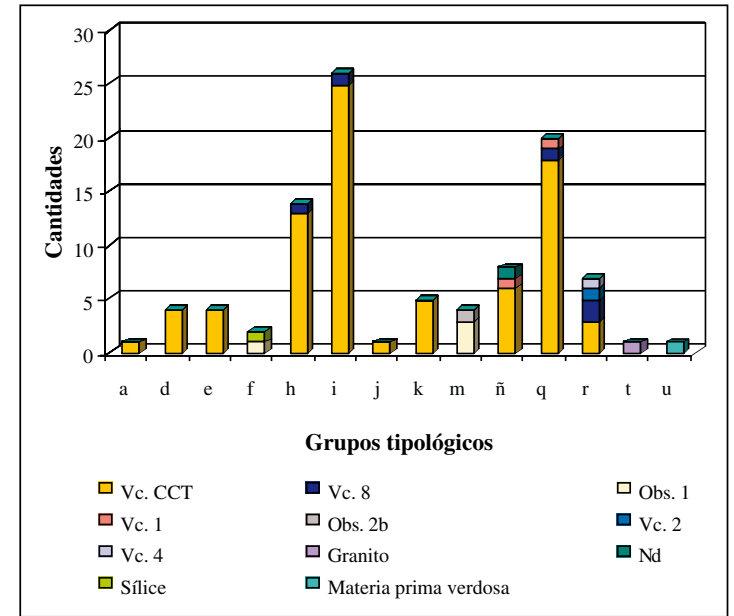

Gráfico 2. Materias primas por grupos tipológicos en Campo Cortaderas 1. Instrumentos ( $\mathrm{n}=98)$.

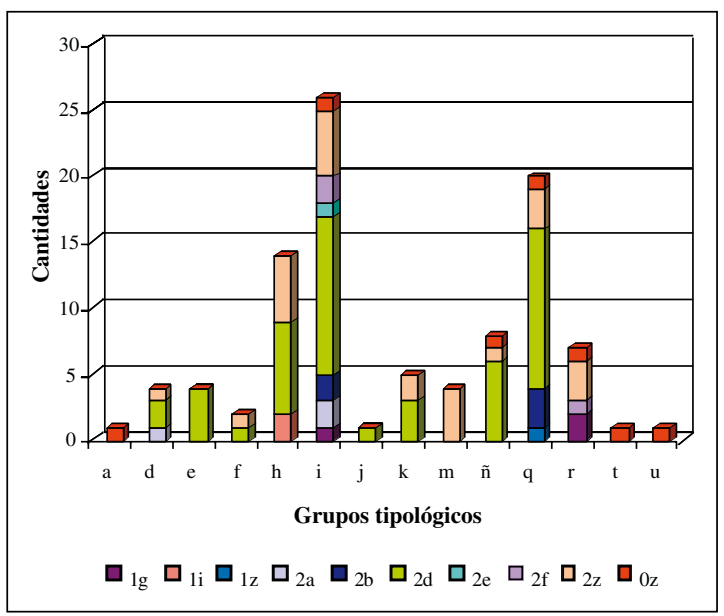

Gráfico 4. Formas bases por grupos tipológicos en Campo Cortaderas 1. Instrumentos ( $\mathrm{n}=98)$.

Grupos tipológicos: (a) percutores; (b) manos; (c) choppers; (d) raspadores; (e) raederas; (f) artefactos mediano-pequeños/muy pequeños con retoque en bisel oblicuo; (g) cortantes; (h) muescas; (i) denticulados; (j) puntas entre muescas; (k) artefactos burilantes; (l) instrumentos

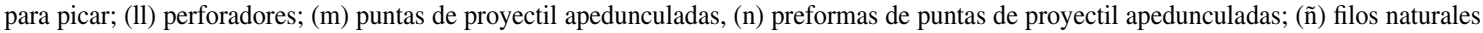
con rastros complementarios; (o) puntas naturales con rastros complementarios; (p) percutores sobre lascas no formatizadas; (q) artefactos de formatización sumaria; (r) fragmentos no diferenciados de artefactos formatizados; (s) palas y/o azadas; (t) artefactos formatizados por picado, abrasión o pulido no diferenciados; (u) cuentas. Materias primas: CC: cuarcita; Obs.: obsidiana; Vc.: vulcanita; Vc. CCT: vulcanita Campo Cortaderas; Vc. Nd: vulcanita no diferenciada; Qz: cuarzo; Vv.: vidrio volcánico; Nd: no diferenciada. Formas bases: (1a) guijarros de sección circular, oval o elíptica muy espesos; (1b) guijarros de sección elíptica, alargados o chatos; (1c) guijarros de sección plano-convexa; (1d) hemiguijarros naturales; (1g) lajas; (1i) clastos o fragmentos angulosos naturales; (1z) nódulos no diferenciados; (2a) lascas primarias; (2b) lascas secundarias; (2c) lascas con dorsos naturales; (2d) lascas angulares; (2e) lascas de arista; (2f) lascas planas; (2z) lascas no diferenciadas; (4j) núcleos sin pátina diferencial; $(0 \mathrm{z})$ formas bases no diferenciadas.

Formatización de los filos de los instrumentos

Para concluir haremos referencia al trabajo en los filos y superficies de los instrumentos en ambos conjuntos. La evidencia nos lleva a sugerir que el mismo no fue intenso. En LA más de la mitad de los filos principales $(n=256)$ presentan retoque y retalla marginal. Les siguen los no pertinentes, dentro de los que incluimos 21 percutores que presentan en sus superficies utilizadas sólo picados y hoyuelos, sin formatización alguna. En lo que atañe al retoque y microrretoque extendido se encuentran muy 


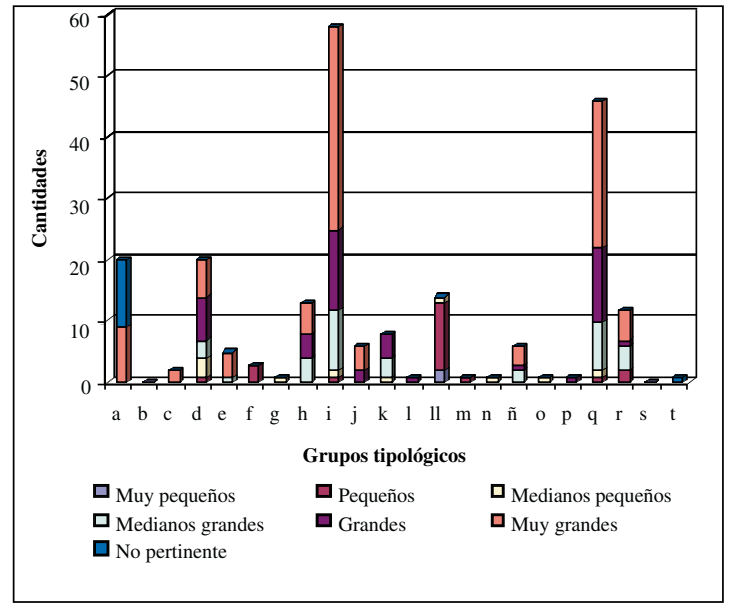

Gráfico 5. Tamaños relativos por grupos tipológicos en La Alumbrera. Instrumentos ( $\mathrm{n}=220$, sin fracturados longitudinal y transversalmente).

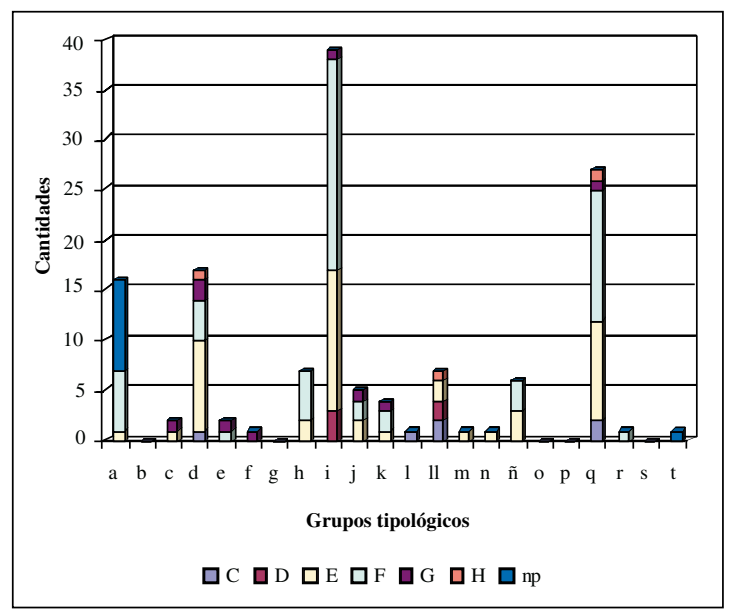

Gráfico 7. Módulos largo-ancho por grupos tipológicos en La Alumbrera. Instrumentos ( $\mathrm{n}=138$, sin fracturados).

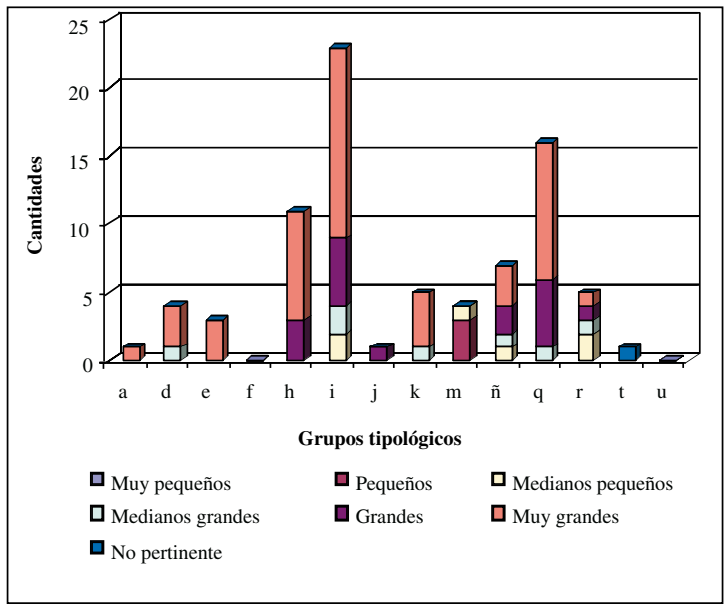

Gráfico 6. Tamaños relativos por grupos tipológicos en Campo Cortaderas 1. Instrumentos ( $\mathrm{n}=81$, sin fracturados longitudinal y transversalmente).

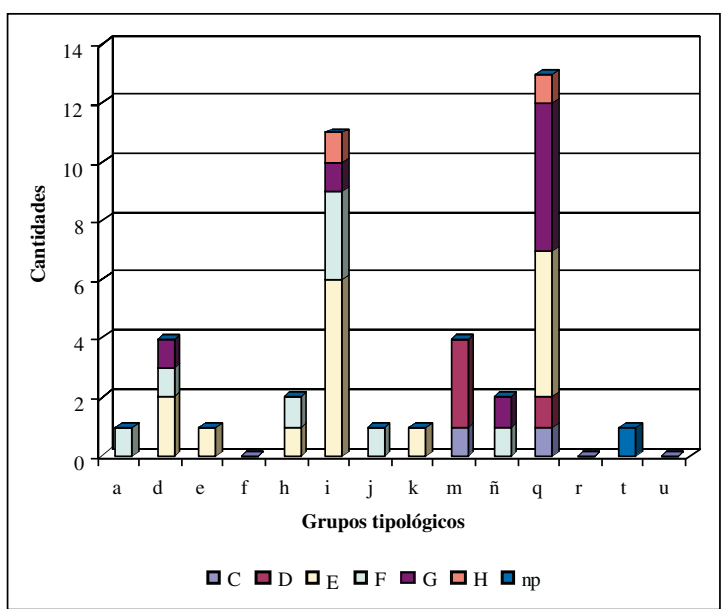

Gráfico 8. Módulos largo-ancho por grupos tipológicos en Campo Cortaderas 1. Instrumentos ( $\mathrm{n}=41$, sin fracturados).

Grupos tipológicos: Ver referencias en Gráficos 1, 2, 3 y 4. Módulos largo-ancho: (C) laminares normales; (D) medianos alargados; (E) medianos normales; (F) cortos anchos; $(\mathrm{G})$ cortos muy anchos; $(\mathrm{H})$ cortos anchísimos; (np) no pertinente.

escasamente representados en el conjunto. Sólo identificamos con estas series técnicas una punta de proyectil apedunculada en obsidiana 3 y un perforador en calcedonia. Asimismo, tampoco los filos formatizados por retalla, retoque y microrretoque parcialmente extendidos alcanzan gran representación en el conjunto. Retoque y microrretoque parcialmente extendidos los hallamos en tres perforadores y en la única preforma de punta de proyectil registrada (Tabla 5).

En CCT1 (n=98) predominan filos obtenidos por retoque marginal, seguidos de los que presentan retalla marginal y retalla y retoque marginal. Incluso dos de los cuatro ejemplares de puntas de proyectil presentan retoque y microrretoque marginal. Sólo dos instrumentos presentan trabajo parcialmente extendido en sus filos. Un artefacto de formatización sumaria con retalla parcialmente extendida y una punta de proyectil con microrretoque parcialmente extendido. Unicamente tres instrumentos muestran trabajo extendido, correspondiendo uno de ellos a un fragmento no diferenciado de artefacto formatizado, otro a una punta de proyectil y el último a un artefacto que presenta picado y alisado extendido (Tabla 5). 


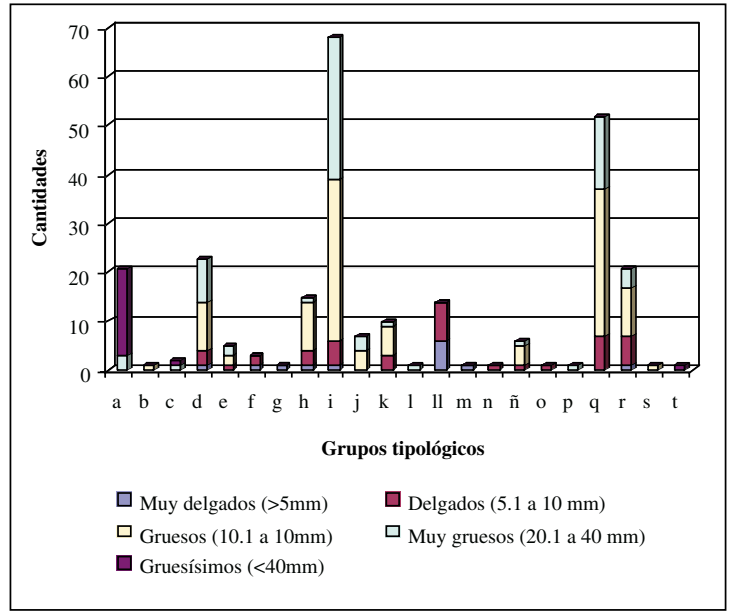

Gráfico 9. Espesores relativos por grupos tipológicos en La Alumbrera. Instrumentos $(\mathrm{n}=256)$.

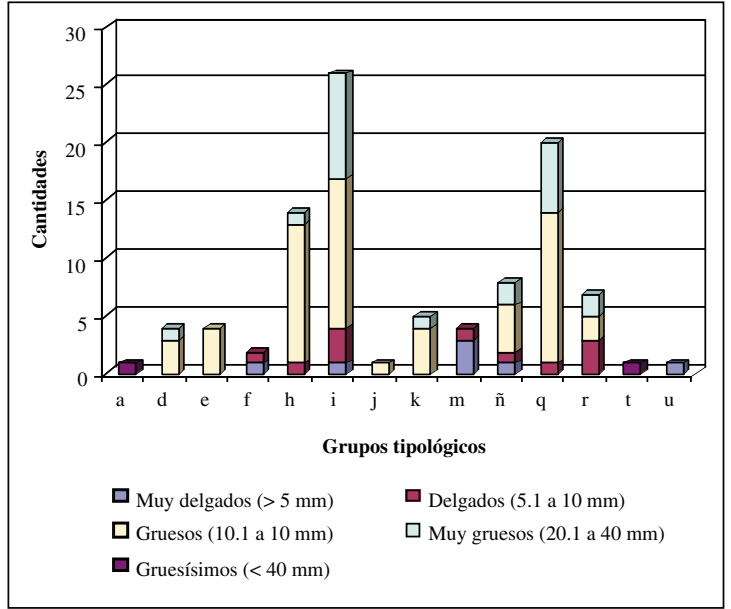

Gráfico 10. Espesores relativos por grupos tipológicos en Campo Cortaderas 1. Instrumentos $(\mathrm{n}=98)$.

Grupos tipológicos: Ver referencias en Gráficos 1, 2, 3 y 4.

\begin{tabular}{|c|c|c|c|c|}
\hline \multirow{2}{*}{$\begin{array}{l}\text { Conjuntos } \\
\text { Series técnicas }\end{array}$} & \multicolumn{2}{|c|}{$\mathbf{L A}$} & \multicolumn{2}{|c|}{ CCT1 } \\
\hline & $\mathbf{n}$ & $\%$ & n & $\%$ \\
\hline Retoque marginal & 98 & 38 & 25 & 27 \\
\hline Retalla marginal & 64 & 25 & 17 & 17 \\
\hline No pertinente & 21 & 8 & 2 & 2 \\
\hline Microrretoque marginal & 15 & 5.9 & 7 & 7 \\
\hline Retalla marginal y retoque marginal & 14 & 5.5 & 17 & 17 \\
\hline Retalla marginal y microrretoque marginal & & & 1 & 1 \\
\hline Con lascado simple de formatización marginal & 9 & 4 & 3 & 3 \\
\hline Talla de extracción sin formatización & 8 & 3 & 8 & 8 \\
\hline Retoque marginal y microrretoque marginal & 8 & 3 & 4 & 4 \\
\hline Retalla parcialmente extendida & 5 & 2 & 1 & 1 \\
\hline Retoque parcialmente extendido & 4 & 1.6 & & \\
\hline Microretoque parcialmente extendido & 3 & 1.2 & 1 & 1 \\
\hline Con lascado simple de formatización marginal y retoque marginal & 2 & 0.8 & 9 & 9 \\
\hline Retoque parcialmente extendido y extendido & 1 & 0.4 & & \\
\hline Retoque extendido y microrretoque marginal & & & 1 & 1 \\
\hline Microrretoque extendido & 1 & 0.4 & 1 & 1 \\
\hline Picado extendido & 1 & 0.4 & & \\
\hline Alisado por abrasión extendido & 1 & 0.4 & & \\
\hline Picado extendido y alisado por abrasión extendido & & & 1 & 1 \\
\hline No diferenciado marginal & 1 & 0.4 & & \\
\hline Totales & 256 & 100 & 98 & 100 \\
\hline
\end{tabular}

Tabla 5. Series técnicas de instrumentos de LA y CCT1.

En CCHM1 Escola (2000: 129-130) señala la misma tendencia. De los 197 artefactos formatizados el $36.6 \%$ presenta retoque marginal y el $14.4 \%$ técnicas de retalla y retoque marginal. A esto debemos agregar 37 FNRC asignables a la categoría talla de extracción sin formatización, 15 percutores, tres manos de molinos, tres fragmentos de molinos y 21 litos modificados por uso, los cuales conforman filos y superficies naturales utilizadas sin formatización (Escola 2000: 149). 
Finalmente, nos interesa destacar que en ambos conjuntos tardíos sobresalen los instrumentos sin filos complementarios, representando en LA $(\mathrm{n}=256)$ el $91 \%$ y en CCT1 (n=98) el 82\% (Elías 2006).

\section{Discusión y conclusiones}

Como dijimos al inicio de este trabajo nos interesa comprender las decisiones tecnológicas líticas de las sociedades tardías y tardías-incas que habitaron la cuenca de Antofagasta de la Sierra y acercarnos al contexto en el cual las mismas habrían sido tomadas.

$\mathrm{El}$ incremento de la sequedad ambiente que se propone hacia $c a .1650$ años AP (Olivera et al. 2004) junto al crecimiento poblacional habrían llevado, no al abandono de la microrregión, sino a la intensificación y extensificación de las prácticas agrícolas (Olivera y Vigliani 2000-2002).

Los riesgos ambientales (p.e., carácter impredecible de las precipitaciones, escasez de agua, pestes) y de producción (p.e., disponibilidad de mano de obra) asociados a la subsistencia productiva, probablemente ya existentes en el contexto de las sociedades agropastoriles formativas (Escola 1996), habrían adquirido gran relevancia entre estos grupos, y con ellos, los mecanismos destinados a minimizarlos (aumento de la capacidad de sustentación para reducir el riesgo productivo, diversificación de las actividades productivas, movilidad, mecanismos sociales de cooperación y almacenaje).

El desarrollo en momentos tardíos y posteriores de estrategias orientadas a aumentar la capacidad de sustentación y la diversificación de las actividades productivas se evidencia en la presencia de amplias superficies con estructuras agrícolas y de sistemas de irrigación a lo largo de distintos sectores de la cuenca como, por ejemplo, Bajo del Coypar I, III y IV y Campo Cortaderas 1, 2 y 3 (Olivera y Tchilinguirian 2000; Olivera et al. 2003-2005). Respecto de la diversificación, es sugerente asimismo lo postulado por López Campeny y colaboradores (2005) respecto a ocupaciones más intensas en los sectores intermedios de Punta de la Peña hacia $c a$. 1200 años AP, tendencia que estaría aconteciendo desde los momentos más tardíos del proceso cultural formativo (ca. 2000 años AP) (Olivera y Podestá 1993). Existen indicios también del incremento de la importancia de las técnicas de almacenaje. En este sentido, Vigliani (1999) señala la destacada representación en la ocupación final de Bajo del Coypar II (posterior a ca. 670 años AP) de cerámica potencialmente asociada por sus características físico-mecánicas con esta actividad (Vigliani 1999; Olivera y Vigliani 2000-2002). La misma tendencia fue señalada entre los materiales de superficie y excavación de LA y CCT1 (Olivera et al. 20032005). Otro ejemplo lo conforman las numerosas estructuras de almacenaje halladas en las paredes de la Quebrada de Petra, con un fechado de 710 \pm 30 AP sobre una muestra tomada de una abundante cantidad de marlos.

Finalmente, las relaciones con los valles mesotermales del este y con otras regiones más alejadas seguirían teniendo un lugar importante entre las estrategias de diversificación y movilidad orientadas a minimizar el riesgo. En este sentido es sugerente la presencia de estilos cerámicos valliserranos en distintos sitios (Yocavil Policromo, Santa María, Belén; Ambrosetti 1906; Olivera 1989, 1991; Olivera et al. 1995), las representaciones rupestres y la presencia de restos vegetales no locales. En el sitio Derrumbes 1, Aschero (1999) señala la presencia del patrón tardío de la representación de la llama reconocido con una notable estandarización entre el Alto Loa y el ámbito valliserrano del Noroeste Argentino. Asimismo, se han relevado en paneles con arte rupestre de la cuenca (p.e., Peñas Coloradas), figuras con formas de escudo, las cuales, también, se registran con alta estandarización a lo largo de las regiones mencionadas.

Respecto de las evidencias vegetales, López Campeny y colaboradores ( $2005 \mathrm{Ms}$ ) señalan la recuperación en niveles tardíos del sitio Piedra Horadada 2, asociados a un contexto ritual, de una alta densidad de restos vegetales no locales, como semillas de chañar, algarrobo, cáscaras de maní y marlos y granos de maíz. Debemos mencionar, asimismo, el registro de restos vegetales foráneos en el sitio Cueva Cacao 1A (Olivera com. pers. 2006).

Por otro lado, probablemente, el incremento de la importancia de la agricultura en la subsistencia habría acrecentado el conflicto entre ésta y el pastoralismo en relación a la distribución de la mano de obra.

Cada una de las estrategias mencionadas, y las actividades implicadas en ellas, demandaron del tiempo de los hombres, por lo que este recurso debió requerir de una cuidadosa administración. 
Entre las diversas actividades desarrolladas por las sociedades pasadas nos focalizamos particularmente en la producción lítica. Nos preguntamos si los cambios señalados hacia el 1000 de la era habrían implicado otros en el rol de la tecnología lítica.

Propusimos que en momentos tardíos y posteriores se habría profundizado la tendencia hacia la minimización del tiempo invertido en las distintas etapas implicadas en la producción de los instrumentos líticos, los cuales responderían a diseños utilitarios (sensu Escola 2000). Asimismo, planteamos que las materias primas seleccionadas serían aquellas que requirieran escasa inversión de esfuerzo en su obtención, encontrándose sus fuentes a muy cortas distancias de los sitios.

Los resultados obtenidos sobre los conjuntos instrumentales de LA y CCT1 y su comparación con los datos obtenidos por Escola (2000) sobre el conjunto instrumental del sitio CCHM1 nos permiten contrastar principalmente la hipótesis $1 \mathrm{~b}$ referida al uso de materias primas muy cercanas en contextos posteriores a $c a .1000$ años AP. Respecto a las hipótesis 1 y 1 a aún se dificulta poder contrastarlas, limitándose nuestro aporte en esta oportunidad a señalar las tendencias observadas en los conjuntos tardíos y tardíos-incas.

Más de las tres cuartas partes de los conjuntos instrumentales de LA y CCT1 se encuentran realizados sobre materias primas espacialmente "muy inmediatas" e "inmediatas", al tiempo que sobre ellas fueron manufacturados más de la mitad de los grupos tipológicos identificados en ambos conjuntos. Esta tendencia podría asimismo relacionarse con el mayor sedentarismo propuesto para momentos posteriores a ca. 1000 años AP (Elías y Escola 2006 Ms).

Por otro lado, muchos instrumentos se hallan también manufacturados, aunque en mucha menor frecuencia, en otros recursos líticos, algunos de probable mejor calidad, tanto en CCT1 como en LA. Sugerimos que cuando otras materias primas se encontraban disponibles eran utilizadas, sin embargo, su no disponibilidad no afectaba la manufactura de los instrumentos y podemos decir que tampoco su uso.

En lo que hace a la etapa de obtención de las formas bases, los resultados nos permiten postular que se habría invertido escaso tiempo y cuidado. Un alto porcentaje de formas bases lascas en LA y CCT1 habrían sido productos de etapas iniciales de re- ducción. Nos arriesgamos a decir que las mismas fueron obtenidas de núcleos amorfos (Aschero 1983 Ms) con limitado control sobre los productos perseguidos. Sin embargo, aún resta el análisis de núcleos y desechos, lo que nos permitirá profundizar en la comprensión de las técnicas de extracción de estos soportes.

También consideramos que limitada estandarización fue buscada entre los soportes sobre los que fueron manufacturados gran parte de los grupos tipológicos. La homogeneidad evidenciada entre las formas bases sobre las que se realizaron distintos tipos, así como que algunos de ellos se encuentren producidos eventualmente sobre lascas con diversas características y otras formas bases (guijarros, clastos angulosos o lajas), podrían constituir argumentos a favor de esta afirmación.

En lo que refiere a la manufactura de los filos y superficies de los instrumentos, observamos las mismas tendencias. Registramos un alto porcentaje de filos y superficies resultados de limitado esfuerzo. Finalmente podemos agregar que incluso entre los instrumentos fracturados predominan los tamaños muy grandes y la ausencia de indicios de intensa reactivación. Sugerimos que, en general, fueron descartados con poco uso y que no fueron mantenidos ni reutilizados. Esto, también, se observa en la presencia de escasos instrumentos con más de un filo (Elías 2006). Entre los tipos que presentan estas características, en LA y CCT1 se hallan los denticulados, raspadores, artefactos de formatización sumaria, muescas, raederas, puntas entre muescas $\mathrm{y}$ artefactos burilantes (Figuras 3 y 4 ).

La ausencia de formas bases altamente estandarizadas y de sobrediseño nos lleva a postular que no responden a diseños confiables (Nelson 1991) adecuados en situaciones de estrés temporal en la obtención de los recursos, donde los tiempos de manufactura y uso de los instrumentos se encuentran desligados. Es más, sugerimos que gran parte de los mismos fueron manufacturados paralelamente a su utilización.

Por otro lado, la ausencia de filos complementarios y la corta vida útil (Shott 1986; Nelson 1991) nos permite plantear que no fueron producto de diseños multifuncionales, y no estarían orientados a responder a situaciones de impredecibilidad en la obtención de los recursos. Dado el contexto en que estos artefactos se presentan, hipotetizamos que la 


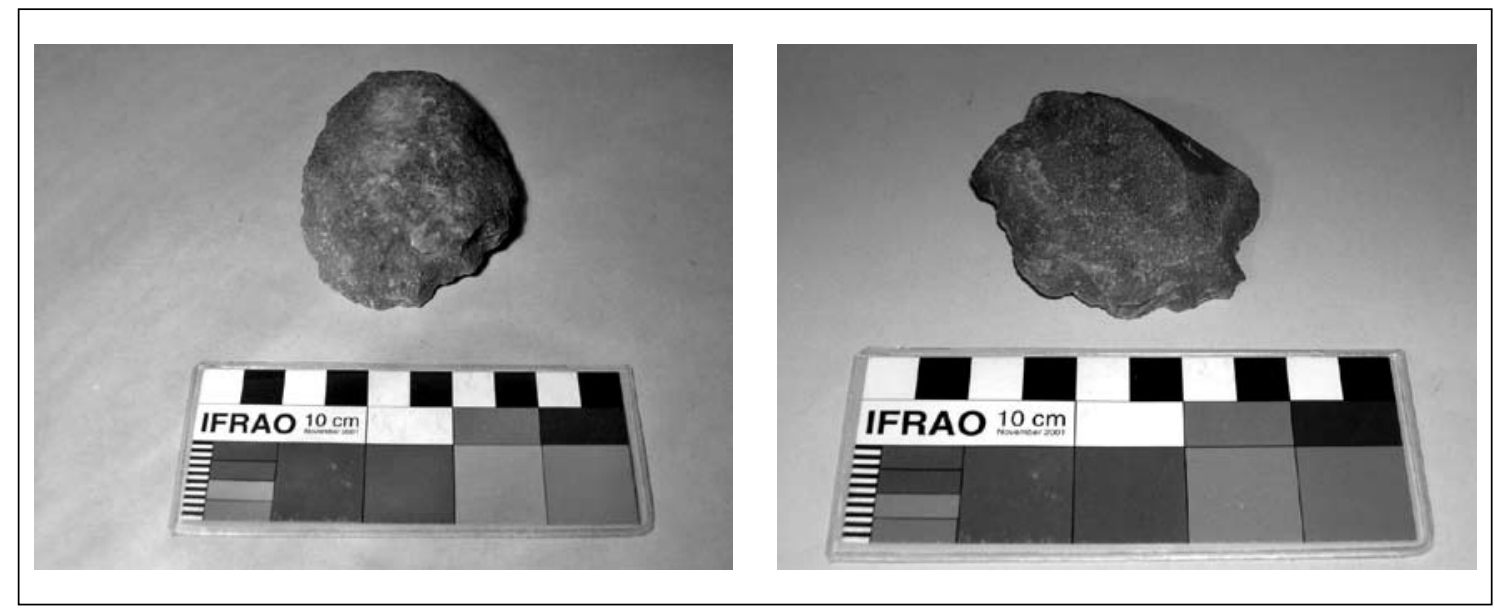

Figura 3. Instrumentos relevados en La Alumbrera.

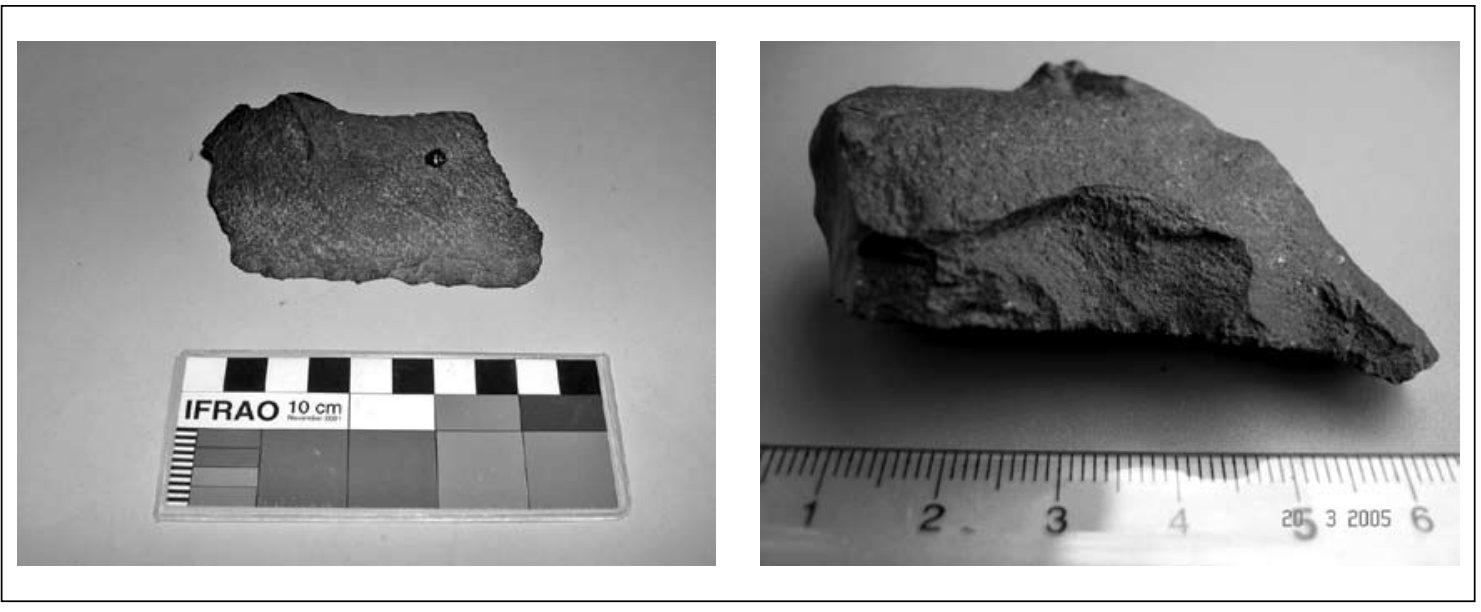

Figura 4. Ejemplos de artefactos con escasa formatización provenientes de Campo Cortaderas 1.

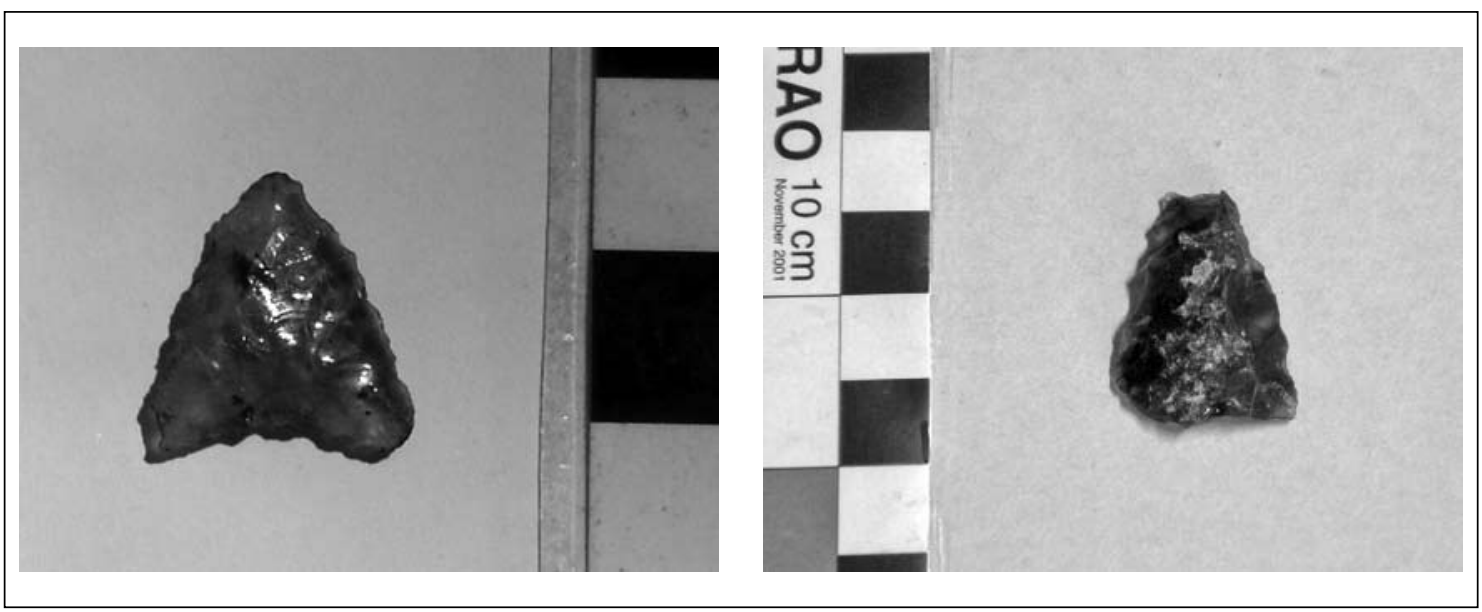

Figura 5. Puntas de proyectil del conjunto instrumental de La Alumbrera. 
presencia de filos complementarios se debería a la reutilización azarosa de ítems disponibles y no a una intencionalidad previa de obtener productos multifuncionales. En relación a esto, creemos que otro factor que habría influido en la ausencia de reutilización y mantenimiento entre los instrumentos estaría relacionado a la alta disponibilidad de recursos líticos con calidades tolerables para su uso por parte de los grupos (Andrefsky 1994).

Ahora bien, los conjuntos analizados revelan mayor heterogeneidad que la postulada en los párrafos precedentes. Esto se evidencia en la existencia de ítems instrumentales que indican ser productos de una manufactura más cuidada y con mayor inversión de esfuerzo en sus distintas etapas. Entre ellos se destacan las puntas de proyectil y los perforadores (Figuras 5, 6 y 7). Sugerimos que son resultado de estrategias conservadas, como nos lo insinúan las materias primas sobre las que fueron manufacturados, la mayor estandarización que evidencian sus soportes y el trabajo, en general, más intenso de sus filos y puntas. Asimismo, ambos habrían sido componentes de aparatos tecnológicos más complejos, compuestos por más de un ítem.

Los perforadores relevados en LA fueron realizados exclusivamente sobre soportes de recursos líticos de textura fina, predominantemente calcedonia, con tamaños pequeños, módulos laminares normales y medianos alargados y espesores delgados y muy delgados. Además, algunos de ellos muestran mayor cuidado en la obtención de sus puntas activas y cuerpos. Estos ítems estarían implicados en la elaboración de otros (p.e., cuentas) que habrían jugado un papel importante en las relaciones con otros grupos. Como
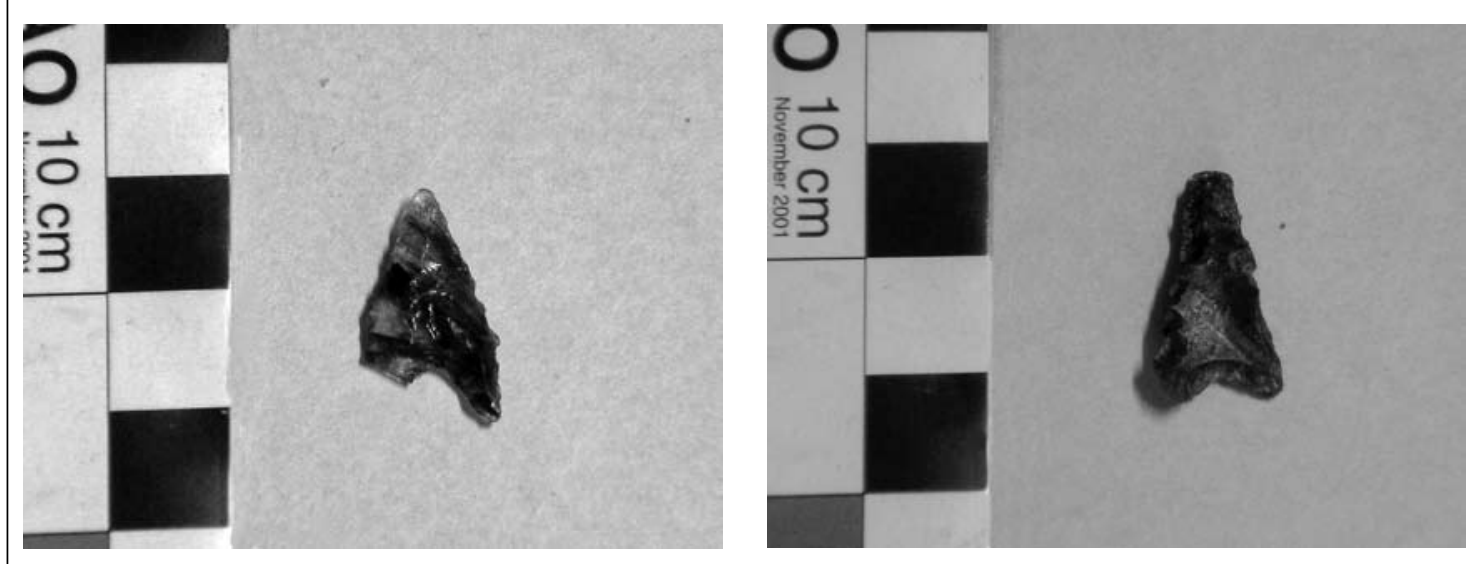

Figura 6. Puntas de proyectil relevadas en Campo Cortaderas 1.

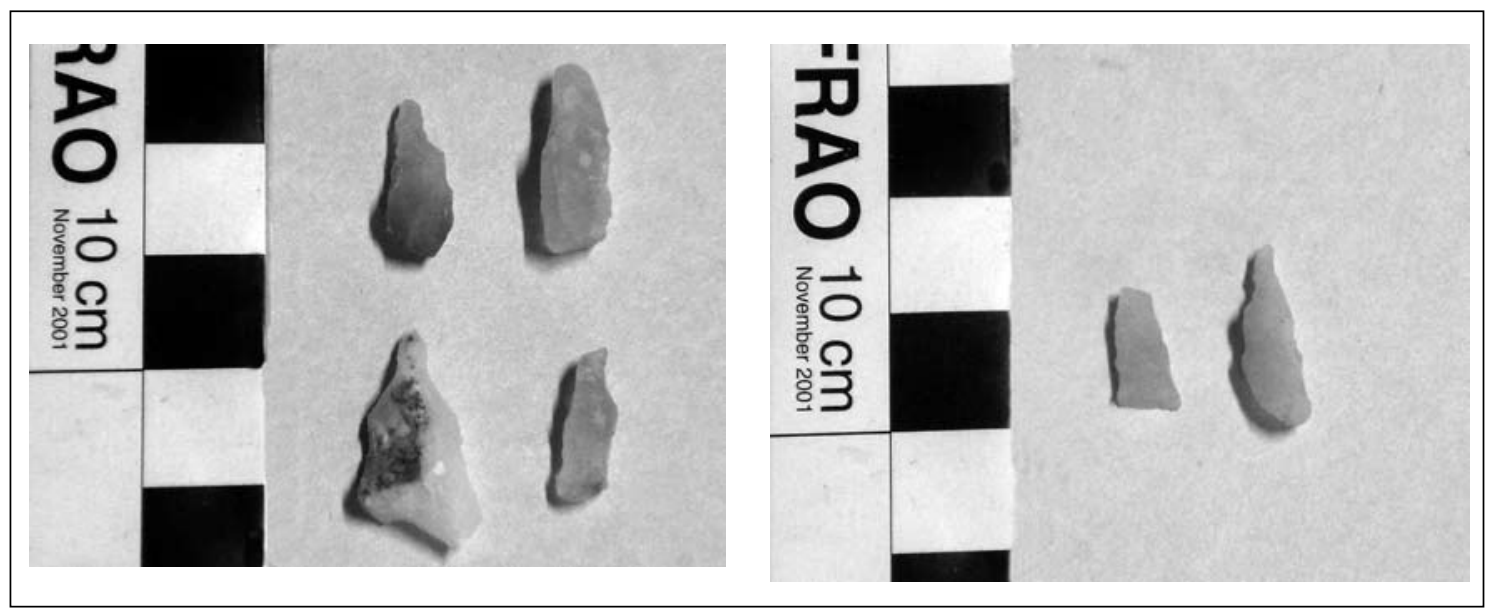

Figura 7. Perforadores relevados en La Alumbrera. 
plantea Torrence (1989), los mecanismos sociales habrían constituido una forma importante de manejo del riesgo en poblaciones con subsistencias basadas en la producción de alimentos. Podríamos esperar que estos mecanismos se hubieran intensificado hacia momentos tardíos en Antofagasta de la Sierra. En este sentido, es prometedor el hallazgo de gran parte de estos útiles concentrados en un recinto del importante asentamiento de LA y asociados a considerables cantidades de desechos de materias primas ligadas a la fabricación de los mismos y de cuentas (Elías 2006).

Las tendencias observadas en las puntas de proyectil son coincidentes con las señaladas para otros conjuntos líticos tardíos, específicamente Bajo del Coypar II. En este último sitio un alto porcentaje fueron manufacturadas sobre formas bases con características similares a las mencionadas y presentan retoque extendido en sus filos (Elías et al. 2001; Escola et al. 2006 Ms). Asimismo, tanto las puntas de proyectil registradas en Bajo del Coypar II como las de CCT1 y LA son apedunculadas con escotadura, lo que nos hace pensar que además se buscó estandarización en el producto final.

Las características presentes en gran parte de estos instrumentos nos llevan a plantear, como ya ha sido sugerido en otras oportunidades (Escola et al. $2006 \mathrm{Ms}$ ), que serían productos de una planificación orientada a enfatizar aspectos de confiabilidad y transportabilidad. Su presencia en los conjuntos y particularidades tecnológicas aportan a la hipótesis de que en momentos tardíos y tardíos-incas la caza habría seguido contribuyendo a la dieta de las poblaciones (Olivera 1998; Olivera et al. 2003-2005), constituyendo, al igual que en el Formativo, una forma de reaseguro del riesgo por medio de la diversificación de la base de recursos (Escola 2002). Los resultados de los análisis iniciales llevados a cabo sobre el material arqueofaunístico de CCT1 avalan esta idea. Si bien muestran una clara presencia de los camélidos domesticados (llama), también algunos huesos corresponderían a vicuña (Lagidium sp.) y aves (Olivera et al. 2003-2005). Consideramos, sin embargo, necesaria una muestra más representativa de estos instrumentos sobre la cual realizar afirmaciones más confiables.

Finalmente, como se deduce de la información desplegada, pocos han sido los ejemplares asociados a actividades agrícolas relevados en los conjuntos, así como exigua la información obtenida relacionada a su diseño, manufactura y uso. En LA se encuentran representados por un fragmento de pala y/o azada lítica y un fragmento de mano, en tanto que en CCT1 por cuatro morteros, sin olvidar los dos ejemplares de palas y/o azadas líticas identificadas durante una temporada de campo anterior. Esta situación es muy distinta a la señalada para CCHM1, donde las palas y/o azadas constituyen el principal grupo tipológico representado y las manos/molinos exhiben mayor frecuencia en el conjunto (Escola 2000).

Morteros, manos y molinos (asignables a momentos posteriores a $c a .3200$ años AP) se han registrado más abundantemente en otras zonas de la microrregión como, por ejemplo, en sitios del río Las Pitas (Babot 2004). También, ejemplares de palas y/o azadas líticas fueron identificados en superficie en las terrazas del área arqueológica de Punta de la Peña.

A pesar de ello, la baja frecuencia de los mismos en los sitios estudiados en esta oportunidad no constituye un hecho aislado y único. Bajo del Coypar II, al cual en sus últimas etapas se lo ha caracterizado como un asentamiento especializado en actividades agrícolas (Olivera y Vigliani 20002002), tampoco muestra ni en superficie (Elías et al. 2001) ni en excavación (Escola et al. 2006 Ms) importante presencia de estos instrumentos. Lo que nos interesa destacar es que en base a la evidencia con la que contamos no observamos que estos útiles hallen mayor representación en los conjuntos analizados ni en otros conjuntos tardíos, acompañando el formulado incremento de la importancia de la agricultura en la subsistencia. Esta baja frecuencia podría explicarse por diversas razones. Una de ellas es el sesgo de la muestra, primordialmente en relación a las tareas iniciales realizadas en CCT1 y LA, lo cual esperamos poder revertir en un futuro cercano. En lo relativo específicamente a los artefactos de molienda, otras razones posibles son: o que los productos principalmente cultivados en la microrregión, que habrían experimentado la intensificación agrícola, no requirieron de esta técnica para su procesamiento, o que otras características de estos ítems más allá de su abundancia en los conjuntos resultaron modificadas. En relación a la última, como señala Babot (2004), a partir de $c a$. 3200 años AP los morteros, manos y molinos, entre otros, muestran evidencias de haber sido diseñados en respuesta a requerimientos de eficiencia e intensificación de la molienda. 
Si bien los artefactos de molienda identificados en ambos sitios aún no han sido objeto de estudios detallados, en lo que refiere a los cuatro morteros registrados en CCT1 muestran ciertas particularidades que condicen con lo observado por Babot (2004) y que los aíslan del común de los instrumentos analizados: estandarización en cuanto a forma y tamaño en el caso de las oquedades y selección de grandes bloques con buena disponibilidad de superficies subplanas naturales.

Con respecto al ejemplar relevado de pala y/o azada lítica, se halla realizado, al igual que sus pares formativos (Escola 2000; Pérez 2003), en una laja de vulcanita 8 , lo que nos lleva a proponer la búsqueda de cierta estandarización en el soporte de este instrumento. Por otro lado, muestra clara evidencia de uso prolongado, alejándose entonces de las tendencias predominantes en ambos conjuntos instrumentales. En relación a su baja frecuencia, nos arriesgamos a proponer que otras materias primas, más específicamente la madera, empezaron a adquirir relevancia en la manufactura de estos ítems en momentos más tardíos. Esta materia prima es ventajosa ya que resulta más liviana que la piedra y más durable (Nelson 1991: 76). Palas de madera de heterogéneas formas y características, que han sido asociadas a actividades agrícolas, se han registrado en diversos sitios arqueológicos tanto en el Noroeste Argentino, como en la región del río Loa (Chile) (Ambrosetti 1907; Boman 1992 [1908]; Debenedetti 1909-1910 Ms; Latcham 1938; Núñez 1974). ${ }^{12}$

Ahora bien, dado que la madera es un recurso limitado en la Puna nos preguntamos ¿cómo las poblaciones habrían accedido a la misma? Una posible respuesta es que haya sido obtenida en la zona valliserrana al este o en otras regiones con las que mantenían contactos. No obstante, estas no son más que algunas ideas respecto a las palas y/o azadas, ya que aún no se han hallado ejemplares que puedan contrastarlas.

Finalmente, deseamos destacar que este trabajo constituye un aporte inicial en el estudio del cambio diacrónico de la tecnología lítica de las sociedades agropastoriles que habitaron Antofagasta de la Sierra a lo largo de los momentos formativos, tardíos y tardíos-incas. Somos conscientes que los conjuntos líticos considerados presentan limitaciones al momento de realizar afirmaciones respecto a esta problemática, dada su procedencia de recolecciones de superficie, la falta de información estratigráfica y fechados absolutos en los sitios considerados, La Alumbrera y Campo Cortaderas 1. En este sentido, esperamos en un futuro cercano disponer de los elementos necesarios para acceder a muestras temporalmente más representativas, las cuales puedan ser analizadas y comparadas a base de similares criterios. Esto nos permitirá alcanzar y contrastar en forma más adecuada los objetivos e hipótesis formulados. Sin embargo, más allá de esto, esperamos que este trabajo contribuya incrementando la información disponible acerca de las estrategias tecnológicas de las sociedades tardías y tardías-incas del Noroeste Argentino (Avalos 2002; Chaparro 2001, 2002; Sprovieri 2005) y, más específicamente, de la microrregión de Antofagasta de la Sierra.

Agradecimientos En primer lugar, al CONICET y al Instituto Nacional de Antropología y Pensamiento Latinoamericano sin cuya colaboración este artículo no podría haber sido escrito. A la comunidad de Antofagasta de la Sierra. A la Dra. Patricia Escola y al Dr. Daniel Olivera por sus sugerencias. A los evaluadores anónimos de Estudios Atacameños, Arqueología y Antropología Surandinas por sus valiosos comentarios que permitieron enriquecer este trabajo, así como análisis futuros. Lo vertido en estas páginas es de mi exclusiva responsabilidad.

12 Debemos mencionar que Delfino y su equipo hallaron un ejemplar de pala de madera en la región de Laguna Blanca (provincia de Catamarca, Puna Meridional Argentina) (Delfino com. pers. 2006). 


\section{REFERENCIAS CITADAS}

ALBECK, M. E., 2001. La Puna Argentina en los Períodos Medio y Tardío. En Historia argentina prehispánica, Tomo I, E. Berberián y A. Nielsen (Eds.), pp. 347-388. Editorial Brujas, Córdoba.

AMBROSETTI, J. B., 1906. Apuntes sobre la arqueología de la Puna de Atacama. Revista del Museo de La Plata XXII: 3-30.

-1907. Exploraciones arqueológicas en la ciudad prehistórica de La Paya (valle Calchaquí, provincia de Salta). Publicaciones de la Sección Antropológica 3. Facultad de Filosofía y Letras, Universidad de Buenos Aires, Buenos Aires.

ANDREFSKY, W., 1994. Raw material availability and the organization of technology. American Antiquity 59 (1): 21-34.

ASCHERO, C., 1975 Ms. Ensayo para una clasificación morfológica de artefactos líticos aplicada a estudios tipológicos comparativos. Informe a CONICET, Buenos Aires.

___ 1983 Ms. Ensayo para una clasificación morfológica de artefactos líticos. Apéndices A y B. Cátedra de Ergología y Tecnología, Universidad de Buenos Aires, Buenos Aires.

-1999. El arte rupestre del desierto puneño y el Noroeste Argentino. En Arte rupestre en los Andes de Capricornio, pp. 97-135. Museo Chileno de Arte Precolombino, Santiago.

ASCHERO, C., P. ESCOLA, S. HOCSMAN y J. MARTINEZ, 2002. Recursos líticos en la escala microrregional Antofagasta de la Sierra, 1983-2001. Arqueología 12. En prensa.

AVALOS, J., 2002. Sistema de producción lítica de una comunidad tardía de la quebrada de Humahuaca. Tesis de Licenciatura en Antropología. Facultad de Humanidades y Ciencias Sociales, Universidad Nacional de Jujuy, San Salvador de Jujuy.

BABOT, M., 2004. Tecnología y utilización de artefactos de molienda en el noroeste prehispánico. Tesis para optar al Grado de Doctor en Arqueología. Facultad de Ciencias Naturales e Instituto Miguel Lillo, Universidad Nacional de Tucumán, San Miguel de Tucumán.

BOMAN, E., 1992 [1908]. Antigüedades de la región andina de la República Argentina y del Desierto de Atacama, Tomo II. Universidad Nacional de Jujuy, San Salvador de Jujuy.

BOYDSTON, R., 1989. A cost-benefit study of functionally similar tools. En Time, energy and stone tools, R. Torrence (Ed.), pp. 67-77. Cambridge University Press, Cambridge.

BROWMAN, D., 1987a. Agro-pastoral risk management in the Central Andes. Research in Economic Anthropology 8: $171-200$.

1987b. Introduction: Risk management in Andean arid lands. En Arid land use strategies and risk management in the Andes. A regional anthropological perspective, D. Browman (Ed.), pp. 1-23. Westview Press, Boulder.
-1994. Información y manejo de riesgo para fleteros de llama en los Andes Centro Sur. Zooarqueología de Camélidos 1, Grupo de Zooarqueología de Camélidos-GZC (Ed.), pp. 23-42. Ediciones del Tridente, Buenos Aires.

CIVALERO, M. T. y N. FRANCO, 2003. Early human occupations in Western Santa Cruz Province, Southernmost South America. Quaternary International 109-110: 77-86.

CHAPARRO, G., 2001. La organización de la tecnología lítica en sociedades pastoriles prehistóricas (desde ca. $2000 \mathrm{AP}$ ) en la quebrada de Inca Cueva: El caso Inca Cueva 5 (Jujuy, Argentina). Arqueología 11: 9-47.

2002. Informe de análisis lítico del sitio Tolombón, provincia de Salta. Trabajo de campo año 2001. Intersecciones en Antropología 3: 119-123.

DEBENEDETTI, S., 1909-1910 Ms. Diario de viaje. V expedición a las regiones del norte argentino.

DELliNO, V., 1998. Puestos de caza y pastoreo de altura: Uso y manejo de recursos líticos en la quebrada de Real Grande (provincia de Catamarca). Tesis de Licenciatura en Ciencias Antropológicas con orientación Arqueología. Facultad de Filosofía y Letras, Universidad de Buenos Aires, Buenos Aires.

ELIAS, A., 2005 Ms. Estrategias tecnológicas y variabilidad de los conjuntos líticos de las sociedades del Período TardíoInca en Antofagasta de la Sierra (provincia de Catamarca). Proyecto presentado a CONICET para acceder a Beca de Postgrado.

2005. Informalidad: Un acercamiento inicial a la tecnología lítica de momentos tardíos a partir de las características de diseño de los instrumentos relevados en dos sitios de Antofagasta de la Sierra (provincia de Catamarca, Argentina): La Alumbrera y Campo Cortaderas. Hombre y Desierto 12: 47-71.

_2006. El estudio de la organización de la tecnología lítica en momentos tardíos ( $c a$. 1000-450 AP) en Antofagasta de la Sierra (provincia de Catamarca). Tesis de Licenciatura en Ciencias Antropológicas con orientación Arqueología. Facultad de Filosofía y Letras, Universidad de Buenos Aires, Buenos Aires.

ELIAS, A. y P. ESCOLA, 2006 Ms. Estrategias de aprovechamiento y uso de recursos líticos en sociedades agropastoriles de la Puna Meridional Argentina. Manuscrito en poder de los autores.

ELIAS, A. y P. TCHILINGUIRIAN, 2006. Aplicación del análisis petrográfico en recursos líticos (Antofagasta de la Sierra, provincia de Catamarca, Puna Meridional Argentina). Actas $1^{e r}$ Congreso Argentino de Arqueometría, Rosario. En prensa.

ELIAS, A., L. PAULIDES y S. VIGLIANI, 2001. Dos astillas del mismo palo: Observaciones tecnológicas preliminares sobre dos sitios de Antofagasta de la Sierra, provincia de Catamarca. Actas XIV Congreso Nacional de Arqueología Argentina. Universidad Nacional de Rosario, Rosario. En prensa. 
ESCOLA, P., 1996. Riesgo e incertidumbre en economías agropastoriles: Consideraciones teórico-metodológicas. Arqueología 6: 9-24.

2000. Tecnología lítica y sociedades agropastoriles tempranas. Tesis presentada para optar al Grado de Doctor en Filosofía y Letras. Facultad de Filosofía y Letras, Universidad de Buenos Aires, Buenos Aires.

2002. Caza y pastoralismo: Un reaseguro para la subsistencia. Relaciones de la Sociedad Argentina de Antropología XXVII: 233-245.

ESCOLA, P., A. ELIAS y L. PAULIDES, 1999. Artefactos líticos en Bajo del Coypar II: Observaciones tecnológicas preliminares. Libro de Resúmenes XIII Congreso Nacional de Arqueología Argentina, pp. 260. Córdoba (1999).

2006 Ms. Bajo del Coypar II: Tendencias tecnológicas para el Tardío de Antofagasta de la Sierra (Catamarca).

FERNANDEZ, M., 1992. The social organization of production in community-based agro-pastoralism in the Andes. En Plants, animals and people: Agropastoral systems research, C. McCorkle (Ed.), pp. 99-108. Westview Press, Boulder.

FRANCO, N., 2002. Estrategias de utilización de recursos líticos en la cuenca superior del río Santa Cruz (Argentina). Tesis presentada para optar al Grado de Doctor en Filosofía y Letras. Facultad de Filosofía y Letras, Universidad de Buenos Aires, Buenos Aires.

GÖBEL, B., 1994. El manejo del riesgo en la economía pastoril de Susques. Zooarqueología de Camélidos 1, Grupo de Zooarqueología de Camélidos-GZC (Ed.), pp. 43-56. Ediciones del Tridente, Buenos Aires.

KOLDEHOFF, B., 1987. The Cahokia flake tool industry: Socioeconomic implications for late prehistory in the Central Mississippi Valley. En The organization of core technology, J. Johnson y C. Morrow (Eds.), pp. 151-185. Westview Press, Boulder y Londres.

LATCHAM, R., 1938. Arqueología de la región atacameña. Prensas de la Universidad de Chile, Santiago.

LOPEZ CAMPENY, S., D. OLIVERA, V. FERNANDEZ VARELA y J. PEÑA, 2005. Procesos tafonómicos, subsistencia y uso del espacio: Análisis de la arqueofauna de un sitio agropastoril de la Puna Meridional Argentina (Punta de la Peña 9, Antofagasta de la Sierra, Catamarca). Intersecciones en Antropología 6: 11-28.

LOPEZ CAMPENY, S., E. DEL BEL, S. RODRIGUEZ CURLETTO y A. ROMANO, 2005 Ms. Evidencias de ritualidad en contextos agropastoriles: El sitio Piedra Horadada 2 ( $\mathrm{PH}$ 2), Puna Meridional Argentina. Ponencia presentada en las VII Jornadas de Comunicaciones, San Miguel de Tucumán.

MELTZER, D., 1989. Was stone exchanged among eastern North American paleoindians? En Eastern paleoindians lithic resources use, C. J. Ellis y J. Lothrop (Eds.), pp. 11-39. Westview Press, Boulder.
MCCORKLE, C., 1992. Agropastoral systems research in the SR-CRSP sociology project. En Plants, animals and people: Agropastoral systems research, C. McCorkle (Ed.), pp. 3-19. Westview Press, Boulder.

NELSON, M., 1991. The study of technological organization. En Archaeological method and theory, vol. 3, M. Schiffer (Ed.), pp. 57-100. The University of Arizona Press, Tucson.

- 1995. Technological strategies responsive to subsistence stress. En Evolving complexity and environmental risk in the prehistoric southwest, J. Tainter y B. Tainter (Eds.), pp. 107144. Proceedings vol. XXIV. Santa Fe Institute Studies in the Sciences of Complexity, Santa Fe.

NUÑEZ, L., 1974. La agricultura prehistórica en los Andes Meridionales. Editorial Orbe, Santiago.

NUÑEZ, L y C. SANTORO, 1988. Cazadores de la Puna Seca y Salada del Area Centro Sur Andina (norte de Chile). Estudios Atacameños 9: 11-60.

OLIVERA, D., 1989. Prospecciones arqueológicas en Antofagasta de la Sierra (Puna Argentina), provincia de Catamarca: Informe Preliminar. Shincal 1: 7-23.

_ 1991. La ocupación inca en la Puna Meridional Argentina: Departamento de Antofagasta de la Sierra, Catamarca. Comechingonia 9 (Tomo especial): 31-72.

_ 1992. Tecnología y estrategias de adaptación en el Formativo (Agroalfarero Temprano) de la Puna Meridional Argentina. Un caso de estudio: Antofagasta de la Sierra (provincia de Catamarca). Tesis para optar al grado de Doctor en Ciencias Naturales. Facultad de Ciencias Naturales, Universidad Nacional de La Plata, La Plata.

-1998. Cazadores y pastores tempranos de la Puna Argentina. En Past and present in Andean prehistory and early history, S. Ahlgren, A. Muñoz, S. Sjodon y P. Stenborg (Eds.), pp. 153-180. Etnologiska Studier 42. Etnografiska Museet, Goteborg.

2006. Recursos bióticos y subsistencia en sociedades agropastoriles de la Puna Meridional Argentina. Comechingonia 9: 19-55.

OLIVERA, D. y M. PODESTA, 1993. Los recursos del arte: Arte rupestre y sistemas de asentamiento-subsistencia formativos en la Puna Meridional Argentina. Arqueología 3: 93-141.

OLIVERA, D. y D. ELKIN, 1994. De cazadores y pastores: El proceso de domesticación de camélidos en la Puna Meridional Argentina. Zooarqueología de Camélidos 1. Grupo de Zooarqueología de Camélidos-GZC (Eds.), pp. 95-124. Ediciones del Tridente, Buenos Aires.

OLIVERA, D. y P. TCHILINGUIRIAN, 2000. De aguas y tierras: Aportes para la reactivación de campos agrícolas arqueológicos en la Puna Argentina. Relaciones de la Sociedad Argentina de Antropología XXV: 99-118.

OLIVERA, D. y S. VIGLIANI, 2000-2002. Proceso cultural, uso del espacio y producción agrícola en la Puna Meridional Argentina. Cuadernos del Instituto Nacional de Antropología y Pensamiento Latinoamericano 19: 459-481. 
OLIVERA, D., P. ESCOLA, J. REALES, M. J. DE AGUIRRE, S. PEREZ, S. VIGLIANI, C. BISSO y S. CAMMINO, 1995. El asentamiento arqueológico de Bajo del Coypar: Una explotación agrícola Belén-Inca en Antofagasta de la Sierra. Actas del XI Congreso Nacional de Arqueología Argentina, Mendoza. En prensa.

OLIVERA, D., S. VIGLIANI, A. ELIAS, L. GRANA y P. TCHILINGUIRIAN, 2003-2005. La ocupación Tardío-Inca en la Puna Meridional: El sitio Campo Cortaderas. Cuadernos del Instituto Nacional de Antropología y Pensamiento Latinoamericano 20: 257-277.

OLIVERA, D., P. TCHILINGUIRIAN y L. GRANA, 2004. Paleoambiente y arqueología en la Puna Meridional Argentina: Archivos ambientales, escalas de análisis y registro arqueológico. Relaciones de la Sociedad Argentina de Antropología XXIX: 229-247.

PARRY, W. y A. CHRISTENSON, 1987. Prehistoric stone technology on Northern Black Mesa, Arizona. Occasional Papers 12. Center for Archaeological Investigations, Southern Illinois University at Carbondale, Carbondale.

PARRY, W. y R. KELLY, 1987. Expedient core technology and sedentism. En The organization of core technology, J. Johnson y C. Morrow (Eds.), pp. 285-304. Westview Press, Boulder y Londres.

PEREZ, S., 2003. Experimentación y análisis de microdesgaste de palas y/o azadas líticas de Antofagasta de la Sierra (Catamarca). Tesis de Licenciatura en Antropología con orientación Arqueología. Facultad de Filosofía y Letras, Universidad de Buenos Aires, Buenos Aires.
_2005 Ms. Aportes metodológicos para el análisis de palas y/o azadas líticas. Manuscrito en poder del autor.

RAFFINO, R. y M. CIGLIANO, 1973. La Alumbrera: Antofagasta de la Sierra. Un modelo de ecología cultural prehispánica. Relaciones de la Sociedad Argentina de Antropología VII (N. S.): 241-258.

SHOTT, M., 1986. Technological organization and settlement mobility: An ethnographic examination. Journal of Anthropological Research 42: 15-51.

SPROVIERI, M., 2005. Manejo de recursos y producción lítica en sociedades tardías del valle Calchaquí (Salta). Tesis de Licenciatura en Antropología con orientación Arqueología, Facultad de Filosofía y Letras, Universidad de Buenos Aires, Buenos Aires.

TORRENCE, R., 1983. Time budgeting and hunter-gatherer technology. En Hunter-gatherer economy in prehistory: A European perspective, G. Bailey (Ed.), pp. 11-22. Cambridge University Press, Cambridge.

1989. Retooling: Towards a behavioral theory of stone tools. En Time, energy and stone tools, R. Torrence (Ed.), pp. 5766. Cambridge University Press, Cambridge.

VIGLIANI, S., 1999. Cerámica y asentamiento: Sistema de producción agrícola belén-inca. Tesis de Licenciatura en Antropología con orientación Arqueología. Facultad de Filosofía y Letras, Universidad de Buenos Aires, Buenos Aires.

YACOBACCIO, H., 1994. Biomasa animal y consumo en el Pleistoceno-Holoceno surandino. Arqueología 4: 43-71. 